\title{
Recent Advances in High Speed Photodetectors for eSWIR/MWIR/LWIR Applications
}

\author{
Baile Chen *(D), Yaojiang Chen (D) and Zhuo Deng (D) \\ School of Information Science and Technology, ShanghaiTech University, Shanghai 201210, China; \\ chenyj@shanghaitech.edu.cn (Y.C.); dengzhuo@shanghaitech.edu.cn (Z.D.) \\ * Correspondence: chenbl@shanghaitech.edu.cn; Tel.: +86-21-2068-5596
}

Citation: Chen, B.; Chen, Y.; Deng, Z.

Recent Advances in High Speed Photodetectors for eSWIR/MWIR/ LWIR Applications. Photonics 2021, 8, 14. https://doi.org/10.3390/ photonics 8010014

Received: 8 December 2020 Accepted: 31 December 2020 Published: 11 January 2021

Publisher's Note: MDPI stays neutral with regard to jurisdictional clai$\mathrm{ms}$ in published maps and institutional affiliations.

Copyright: (C) 2021 by the authors. Licensee MDPI, Basel, Switzerland. This article is an open access article distributed under the terms and conditions of the Creative Commons Attribution (CC BY) license (https:// creativecommons.org/licenses/by/ $4.0 /)$.

\begin{abstract}
High speed photodetectors operating at a telecommunication band (from 1260 to $1625 \mathrm{~nm}$ ) have been well studied with the development of an optical fiber communication system. Recent innovations of photonic systems have raised new requirements on the bandwidth of photodetectors with cutoff wavelengths from extended short wavelength infrared (eSWIR) to long wavelength infrared (LWIR). However, the frequency response performance of photodetectors in these longer wavelength bands is less studied, and the performances of the current high-speed photodetectors in these bands are still not comparable with those in the telecommunication band. In this paper, technical routes to achieve high response speed performance of photodetectors in the extended short wavelength infrared/mid wavelength infrared/long wavelength infrared (eSWIR/MWIR/LWIR) band are discussed, and the state-of-the-art performances are reviewed.
\end{abstract}

Keywords: high-speed photodetectors; eSWIR; MWIR; LWIR

\section{Introduction}

Semiconductor photodetectors convert incident light into electrical current with advantages in reliability and fast response speed. Since being developed in 1960s, they have been used in imaging, sensing, and communication applications. The rapid progressing of information technology, especially in communication systems, has raised the demand for photodetectors with high bandwidth. The response speed is an essential figure of merit in optical fiber communication systems operating from 1260 to $1625 \mathrm{~nm}$.

In fiber communication systems, the transmission capacity is limited by the linearity of the fiber and available bandwidth [1]. Compared to solid core silica fiber, hollow core photonic bandgap fiber which operates at $2 \mu \mathrm{m}$ wavelength with lower nonlinearity and ultra-low latency [2], together with the thulium doped fiber amplifier which provides wide wavelength demultiplexing (WDM) bandwidth [3], can potentially enable the higher capacity of optical communication system at around $2 \mu \mathrm{m}$ [4-8]. These also raise the demands for high-speed photodetector functioning in the 2- $\mu \mathrm{m}$ band.

Besides fiber communication, free space optical (FSO) communication also plays an important role in modern communication systems, especially for local area networks and inter-building connections $[9,10]$. One of the challenges of FSO in atmospheric environment is the light scattering and decaying in a foggy or dusty environment [11]. The MWIR/LWIR range optical signal can propagate through the atmosphere much farther than the nearinfrared band, which makes these wavelengths attractive for free space communication. However, the FSO system is often limited by the bandwidth performance of MWIR/LWIR light sources and photodetectors [12].

Recent development of infrared frequency combs sources have brought new opportunities to frequency comb spectroscopy, which provides wide spectral range, precise resolution and fast acquisition time $[13,14]$. In the MWIR and LWIR range, frequency combs could be very useful for the precise definition of the molecular hyperfine structure. The high precision of this technique relies on the detection of radio frequency pulse trains 
and thus requires high-speed photodetectors in the corresponding band. High-speed photodetectors are also key components in light detection and ranging (LIDAR) systems for applications such as gaseous $[15,16]$ and automotive sensing $[17,18]$.

This paper reviews the bandwidth characteristics of high-speed photodetectors operating in a wavelength beyond the L-band (from 2 to $10 \mu \mathrm{m}$ ), which have been rarely reviewed before. The materials selections, device structures, device performances, and device characterization techniques are discussed.

\section{Design Consideration of High-Speed Photodetector}

\subsection{Cut-Off Wavelength}

Infrared detectors are broadly classified into thermal detectors and photon detectors. Thermal detectors measure the power of incident electromagnetic radiation via one of the secondary effects associated with infrared radiation, such as the increase of temperature. These detectors can operate at room temperature but are not very suitable for high-speed, high-sensitivity applications. One the other hand, the principle of the photon detector involves the change in electrical properties of a material associated with the absorption of photons. Photon detectors can be further classified into photovoltaic (PV) and photoconductive (PC) detectors. Photovoltaic detectors are diodes which produce a voltage across the terminals when photons are absorbed. These diodes can be operated at zero bias, but are often reverse biased to produce a higher electrical field in the depletion region of the $\mathrm{p}-\mathrm{n}$ junction. The photo-generated carriers in the depletion region will be drifted to the electrodes and will cause an increased reverse current. Photoconductive detectors are made of the materials whose conductivity increases with incident radiation intensity due to the photo-generated carriers. External bias is needed for a PC detector, since no potential difference is created across the terminal under radiation. Generally speaking, PV detectors have a higher signal-to-noise ratio than PC detectors.

PV detectors are usually based on interband absorption. In order to detect photons at a particular wavelength, the energy gap in the photodetectors must be lower than the energy of the incident photon. For long cut-off wavelength detection, narrow bandgap materials are usually utilized at the corresponding infrared band. The composition of ternary or quaternary compounds such as InGaAs, GaInAsSb, and $\mathrm{HgCdTe}$ can be adjusted to get the target bandgap, but the strain induced by lattice-mismatch has to be carefully considered, otherwise the defects induced could cause a significant leakage current. Thanks to the very close lattice constant between $\mathrm{HgTe}$ and CdTe, it is possible to grow $\mathrm{Hg}_{1-\mathrm{x}} \mathrm{Cd}_{\mathrm{x}} \mathrm{Te}$ alloy with cut-off wavelength from 1 to $30 \mu \mathrm{m}$ [19]. These HgCdTe photodetectors can absorb the IR radiation across the fundamental energy gap, and have high quantum efficiency due the large optical absorption coefficient. Moreover, the HgCdTe detectors also have a relatively low thermal generation-recombination rate which results in a higher operation temperature compared with other approaches. These makes HgCdTe a predominant option for MWIR/LWIR photodetection. However, $\mathrm{HgCdTe}$ has serious technological problems in mass production due to its weak Hg-Te bond [20]. Moreover, $\mathrm{HgCdTe}$ detectors suffer from poor material uniformity, low yield, high cost in growth and processing, and surface instability [21]. These material difficulties have made it necessary to examine the performance of alternative material systems.

The invention of type-II band alignment using antimonide based material brings more possibility of infrared photodetection, which is also based on interband absorption. With the type-II band alignment, the effective bandgap of type-II super lattice (T2SL) or type-II multiple quantum wells (MQWs) can be narrower than that of the individual constituent materials. The type-II InAs/GaSb/AlSb superlattice systems on GaSb or InAs substrate are suitable for SWIR, MWIR, and LWIR detection by bandgap engineering, while retaining lattice-matched or strain-balanced conditions. Compared with $\mathrm{HgCdTe}$ photodetectors, T2SL has lower Auger recombination and band-to-band tunneling and thus could potentially offer a lower dark current [22]. With the use of a barrier layer, room temperature operation of T2SL is demonstrated at the MWIR band [23]. Recently, Ga- 
free InAs/InAsSb T2SLs emerged as an alternative with simpler growth and significantly longer minority lifetime compared to InAs/GaSb T2SL [24,25]. Meanwhile, InP-based T2SL using InGaAs/GaAsSb materials are usually used in e-SWIR detection [26-30]. There are a number of advantages in using an InP substrate, e.g., mature device fabrication, material epi-growth, availability of high-quality 6-inch InP substrates, etc. Since these super lattices structure can be grown on InP substrate using lattice matched or strain compensated InGaAs and $\mathrm{GaAsSb}$ materials, the generation of crystal defects by the lattice mismatch issue can be eliminated. Therefore, lower dark currents can be expected compared to the InP-based In-rich InGaAs devices, which is a common material candidate for the eSWIR region.

Besides interband absorption, absorption based on inter-subband transition can also be utilized for eSWIR/MWIR/LWIR detection. These devices are often based on the photoconductor effect (PCE) instead of the photovoltaic effect (PVE), where the device resistance changes under illumination by applying an external bias across the detector and measuring the current simultaneously. A quantum well infrared photodetector (QWIP) is one of the most popular examples based on inter-subband transition-based devices, which is believed to be an alternative to $\mathrm{HgCdTe}$ with good uniformity and thus lower cost [31]. In n-type QWIPs, the electrons in the ground state of the QWs are excited to a higher level and contribute to photocurrents by absorption of photons. The schematic of conduction band diagram of a QWIP is shown in Figure 1 [32]. Utilizing the intersubband transition within the GaAs/AlGaAs quantum wells, a peak detection wavelength ranging from 8 to $12 \mu \mathrm{m}$ can be achieved. In addition, with the strained InGaAs/AlGaAs quantum wells, the MWIR range can also be covered [33]. QWIPs are able to achieve higher response speed due to the intrinsic short carrier lifetime [34,35]. However, one drawback of QWIPs is the low quantum efficiency, and the cryogenic operation condition in order to suppress the dark current [31]. Another disadvantage of QWIPs is that normal incidence absorption is forbidden in n-doped QWIPs, due to the quantum mechanical selection rule in the $\Gamma$-symmetry conduction band [31]. An efficient optical coupling scheme such as using diffraction gratings is needed for normal incidence detection. P-type QWIPs could detect normal incident light; however, the absorption, responsivity, and response speed are much lower due the larger effective mass and lower mobility of holes.

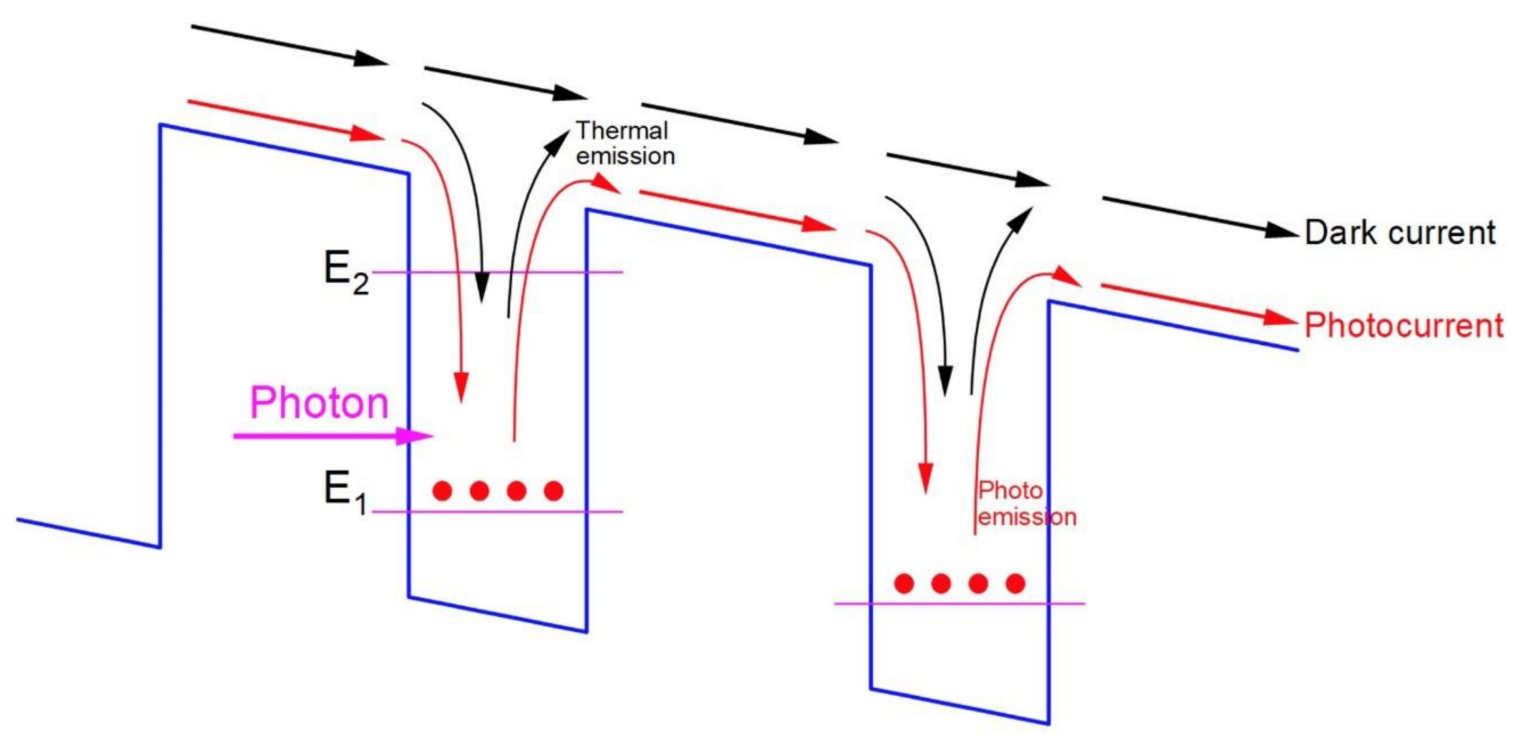

Figure 1. Conduction band diagram of quantum well infrared photodetectors. Reproduced from Ref. [32], with permission of American Institute of Physics (AIP) Publishing.

Quantum dot infrared photodetectors (QDIPs) are operated in a similar manner as QWIPs. The only difference is that the carriers in a QDIP are confined in 3D rather than 1D. This 3D confinement of carriers in QDs provides the unique properties of QDIPs. QDIPs are intrinsically sensitive to normal incidence due to the breaking of quantum mechanical 
selection rule. Theoretical work predicted that QDIPs could have lower dark currents than QWIPs because of weaker thermionic emission from the QDs with 3D confinement [36]. However, QDIPs generally have a low quantum efficiency and absorption coefficient due to the small fill factor of QDs and inhomogeneous broadening of the self-assembled QDs [37].

\subsection{Response Speed}

The response speed of the photodetector is an important figure of merit in various applications as mentioned above. The limiting factors of photodetectors and methods to improving the response speed are well studied. The response speed of the photodetector usually depends on the carrier transport within the device, and the circuit dynamics in the lumped element model. A 3-dB bandwidth can be used to characterize the response speed, which is limited by [38]:

$$
f_{3-\mathrm{dB}}=\left(f_{t}^{-2}+f_{R C}{ }^{-2}\right)^{-1 / 2}
$$

where $f_{t}$ is the transit time limited bandwidth, and $f_{R C}$ is the RC time limited bandwidth. The transit time corresponds to the time that photogenerated carriers take to be collected. For an ideal p-i-n photodiode, the transit time is proportional to the thickness of depletion region over the carrier velocity [39]. Reducing the thickness of the depletion region will increase the transit time limited bandwidth, but leads to a lower quantum efficiency. Moreover, the decrease of depletion region thickness could lead to a larger junction capacitance, which will reduce the RC time limited bandwidth. The RC time limited bandwidth is often derived from the equivalent circuit model of the photodetector. The existence of junction capacitance together with the parasitic capacitance leads to a low-pass filter effect. In this way, a smaller active area is preferred in order to achieve a high response speed. Effenberger and Joshi proposed dual depletion region photodetector with optimized absorption region thickness and drift region thickness at $1550 \mathrm{~nm}$, which balance the transit time limited and RC time limited bandwidth [40].

In order to achieve a higher transit time limited bandwidth, besides applying a strong electric field to accelerate the carriers, some novel design structures such as uni-traveling carrier (UTC) photodiodes are proposed and demonstrated to eliminate the slow transport of hole carriers. In traditional p-i-n photodiodes, the light absorption occurs in the intrinsic region, and electron-hole pairs are generated, where slow hole transport often limits the bandwidth of photodiodes. In UTC photodiodes, the photogenerated electron-hole pairs are created in the undepleted p-type absorption region, and the excess hole carriers will relax within a sub-picosecond time duration, due to the quick dielectric relaxation process. The transport of electrons is generally much faster than hole transport, leading to higher bandwidth when compared with the p-i-n photodiodes [41]. UTC photodiodes with bandwidth above $300 \mathrm{GHz}$ have been demonstrated at $1550 \mathrm{~nm}$ [41]. The band diagrams of the traditional p-i-n PD and the UTC-PD with InGaAs as absorber are schematically shown in Figure 2a,b.

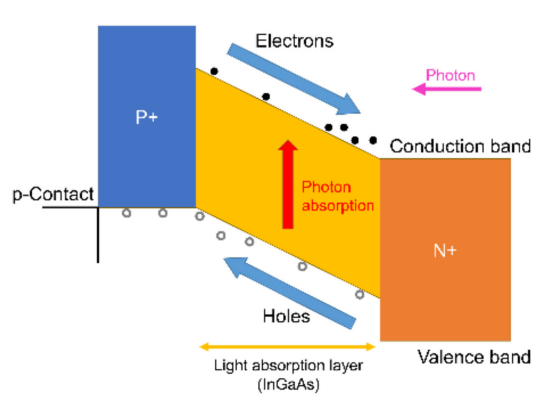

(a)

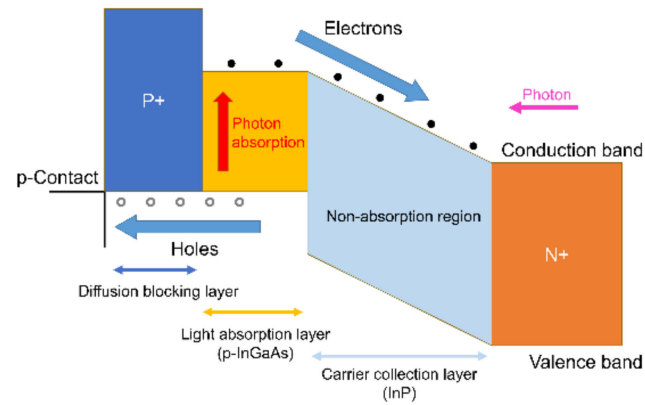

(b)

Figure 2. Band diagrams of (a) conventional p-i-n photodiode and (b) uni-traveling-carrier photodiode. 
For high speed light detection at wavelength in MWIR and LWIR, QWIPs are very promising candidates. The picosecond-level inter-subband electron scattering time and high electron mobility could help QWIPs achieve $>100 \mathrm{GHz}$ bandwidth. There are different types of inter-subband transitions for QWIPs, such as bound-to-bound, bound-to-resonant, and bound-to-continuum. The bound-to-bound transition devices often have a large absorption coefficient per well due to the small final state broadening. However, the carrier extraction efficiency could be an issue due to the energy level difference between the first excited state and the barrier's conduction band edge, which could degrade the responsivity and bandwidth performance. The bound to continuum transition QWIPs have a broader and asymmetrical absorption spectrum with a low absorption peak [42]. Optimum QWIPs for high speed and a high responsivity operation are usually based on the bound-to-resonant transition, with the upper state (the first excited state) nearly in resonance with the barrier height [43]. The active region consists of identical QWs separated by significantly thicker barriers to avoid coupling between different QWs. The QW thickness and conduction band offset is carefully chosen so that the first excited state in the QW is close to resonance with the conduction band edge of a barrier to ensure a good carrier extraction efficiency for high speed and a high responsivity operation.

Quantum cascade detectors (QCDs) are originally proposed with the advantage of zero bias operation and improved signal to noise ratio as compared with the QWIPs structure [44], which is essential for MWIR and LWIR operation since noise level often limits the sensitivity of the devices. The band diagram of QCD is shown in Figure 3. QCDs have multiple-stage architecture, and each stage is composed of two regions: the absorption region and the carrier extraction region. The photogenerated carriers only need to transport one single stage before relaxing to the ground state of the next stage. Therefore, this multiple-stage architecture of QCD could help improve the device bandwidth. In QCDs, after absorbing the IR light, the electrons in the ground state ( $E_{1}$ in Figure 3 ) will be excited to the first excited state $\left(E_{2}\right.$ in Figure 3$)$ and then transport into $E_{3}$ through resonant tunneling and the other subsequent extractor states (such as $\mathrm{E}_{4}, \mathrm{E}_{5}, \mathrm{E}_{1}^{\prime}$ ) by phonon assisted scattering to complete one stage transport. To achieve a fast and efficient electron extraction through phonon-electron scattering, the energy difference between the individual extractor states should be close to the longitudinal optical phonon energy, which is critical for high speed operation.

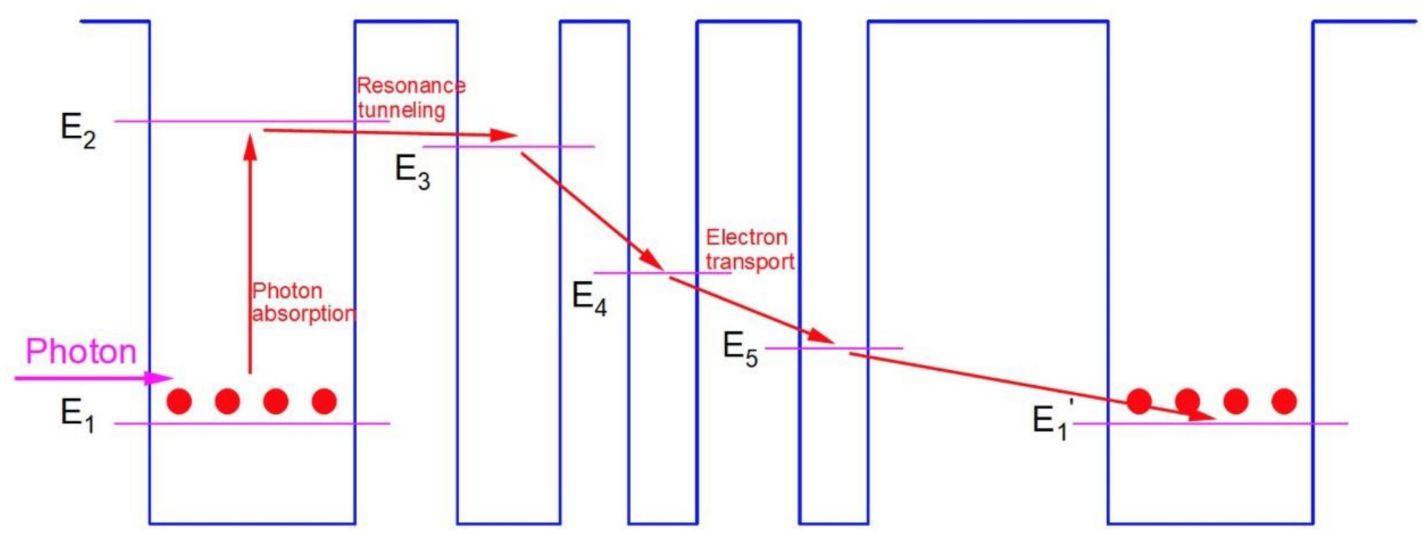

Figure 3. Conduction band of quantum cascade photodetectors. Reproduced from Ref. [32], with permission of AIP Publishing.

Interband cascade infrared photodetectors (ICIPs) operate with a similar principle as QCDs by incorporating multiple stage architecture, with the main difference being that the ICIP device is based on interband transitions. One commonly studied material system for ICIP is the InAs/AlSb/GaSb $6.1 \AA$ A family. ICIPs consist of an absorption region, electron injector region, and hole injector region. The electron injector region also works as the hole barrier designed with InAs/AlSb QWs by gradually varying the InAs thickness, while the hole injector region also serves as the electron barrier composed of $\mathrm{GaSb} / \mathrm{AlSb}$ 
QWs. The schematic band diagram for one and half stages of an ICIP is shown in Figure 4. Like QCDs, the photogenerated carriers travel only over one cascade stage before they recombine in the next stage. The thickness of the absorber in every individual cascade stage can be significantly shorter than the diffusion length of InAs/GaSb, while the total thickness of all the absorbers can still be longer than the diffusion length. Hence, this could circumvent the tradeoff between absorption efficiency and carrier extraction efficiency in traditional p-i-n like structures, given the limited diffusion length of InAs/GaSb T2SL especially at high temperatures. Meanwhile, carrier transit time can be designed to be short with multiple stages, while maintaining a high absorption efficiency and thus a high sensitivity [45]. Compared to QCDs with picosecond level phonon-scattering lifetime, ICIPs usually have a lifetime in nanosecond level lifetime due to the Shockley-Read-Hall (SRH) and Auger recombination. This helps ICIPs to achieve higher peak responsivity and lower dark current density than QCDs with a similar transition wavelength [46]. However, for high speed operation, short carrier lifetimes could be beneficial in QCDs. As will be shown in the next section, the 3-dB bandwidth of the state-of the-art ICIPs is still below $10 \mathrm{GHz}$, while QCDs can achieve a much higher bandwidth as close to that of QWIPs due to the short excited state carrier lifetime.

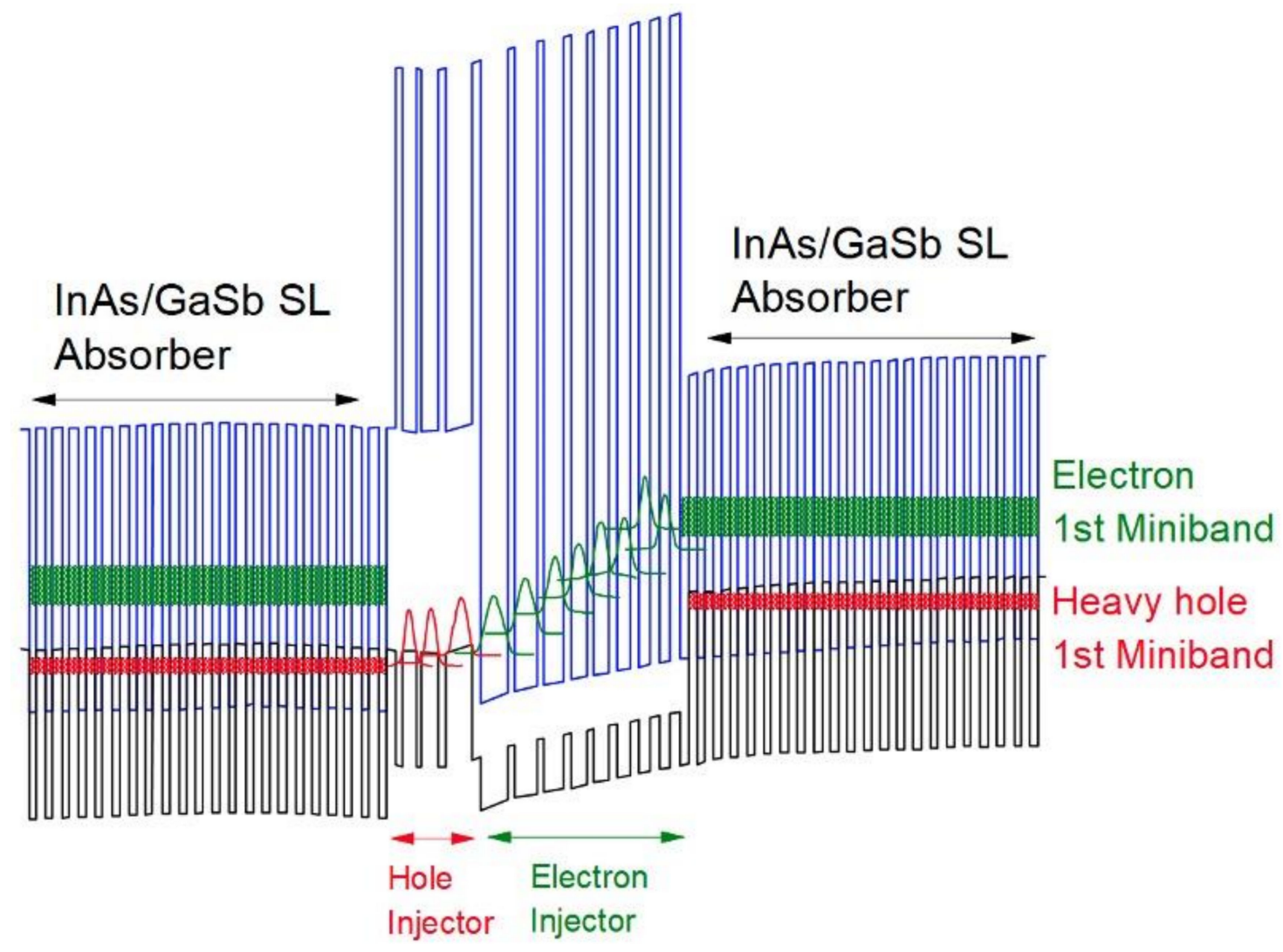

Figure 4. Schematics of the band profiles of interband cascade detector with a small reverse bias. Reproduced from Ref. [47], with permission of AIP Publishing.

\section{States-of-the-Art for High Speed Infrared Photodetectors \\ 3.1. For eSWIR Operation}

Silicon material has been widely used in semiconductor photodetectors, benefiting from its low cost and high crystal quality. Although the cut-off wavelength of a siliconbased photodetector is only around $1.1 \mu \mathrm{m}$, it can be extended to $1.6 \mu \mathrm{m}$ by epitaxially growing germanium on silicon substrate, to support the telecommunication band at 1.3 and $1.55 \mu \mathrm{m}$ [48-50]. Similar methods can be proceeded beyond $1.7 \mu \mathrm{m}$ by introducing tin to form germanium-tin (GeSn), of which the cut-off wavelength can be extended to 
larger than $2 \mu \mathrm{m}$. With Sn-composition of 0.09 , a cut-off wavelength of $2.4 \mu \mathrm{m}$ can be achieved in strained GeSn/relaxed Ge MQWs absorber grown on silicon [51]. The p-i-n photodiode with $\mathrm{Ge}_{0.92} \mathrm{Sn}_{0.08}$ absorber and strained Ge buffer layer on Si substrate is also reported to cut-off at $2.3 \mu \mathrm{m}$ [52]. With GeSn/Ge MQWs absorber, a 3-dB bandwidth of over $10 \mathrm{GHz}$ was achieved at $2 \mu \mathrm{m}$ operation [53,54]. Furthermore, with GeSn absorption layer, a $1.78 \mathrm{GHz}$ bandwidth of for p-i-n photodiode was reported at $2 \mu \mathrm{m} \mathrm{[55],} \mathrm{which} \mathrm{was}$ limited by mesa diameter. GeSn based photodetector is attractive for its compatibility to Si based CMOS technology, which is beneficial to multi-functional opto-electronic integration and cost reduction [52]. However, given the notable lattice mismatch between GeSn and Si substrate, the performance of GeSn device is still limited by the high dark current and low responsivity. For typical GeSn devices reported in the literature $[53,54]$, the room temperature dark current density at $-1 \mathrm{~V}$ is around $42 \mathrm{~mA} / \mathrm{cm}^{2}$, and the optical response at $2 \mu \mathrm{m}$ is around $0.015 \mathrm{~A} / \mathrm{W}$. Although using photon-trapping microstructure could help improve the quantum efficiency of GeSn/Ge MQWs with a slight increase of dark current [56], the performance is still inferior to III-V devices working in similar wavelength range $[57,58]$.

Another Si-based method is to utilize the defect-mediated absorption mechanism in silicon, which was demonstrated for $1.55 \mu \mathrm{m}$ photodetection [59-61]. Optical absorption at wavelength of $2.3 \mu \mathrm{m}$ is demonstrated with low-dose inert ion implantation and $200-350{ }^{\circ} \mathrm{C}$ annealing [62]. The process is also CMOS-compatible and so the device can be easily integrated with other silicon devices. The drawback is that the responsivity is low, and so an avalanche operation is necessary for high performance. Ackert et al. demonstrated a silicon-based photodiode operating in $2 \mu \mathrm{m}$ band on a silicon-on-insulator waveguide [63]. The external responsivity at $2 \mu \mathrm{m}$ is around $0.3 \mathrm{~A} / \mathrm{W}$ at a bias of $30 \mathrm{~V}$, with a dark current less than $1 \mu \mathrm{A}$ for a 1-mm-long photodiode. With a $200 \mu \mathrm{m}$-level length absorption region, the device shows a 3-dB bandwidth of $15 \mathrm{GHz}$ measured by a $1550 \mathrm{~nm}$ laser source, and a $28 \mathrm{Gbit} / \mathrm{s}$ data rate can be achieved at $27 \mathrm{~V}$ bias voltage with a $1960 \mathrm{~nm}$ laser source.

Lattice matched $\operatorname{In}_{0.53} \mathrm{Ga}_{0.47}$ As on InP substrate has long been used in the optical communication for its fast carrier transport and high absorption at $1.55 \mu \mathrm{m}$ wavelength $[64,65]$. The lattice matched InGaAs have an optical response cut off at $1.7 \mu \mathrm{m}$. By increasing indium composition, the detection wavelength of InGaAs can be increased. For example, with indium composition larger than 0.7 , the cut-off wavelength of $\operatorname{In}_{x} \mathrm{Ga}_{1-x}$ As on $\operatorname{InP}$ can be extended to $2 \mu \mathrm{m}[66]$ or even longer $[67,68]$. However, the defects associated with the lattice mismatch between InGaAs and InP substrate could propagate into the active region and lead to high dark current [69]. Joshi et al. has demonstrated $\operatorname{In}_{0.72} \mathrm{Ga}_{0.28} \mathrm{As} \mathrm{p}-\mathrm{i}-\mathrm{n}$ high speed photodetector with $6 \mathrm{GHz}$ bandwidth at $2 \mu \mathrm{m}$ p-i-n by applying lower load resistor (effectively $25 \Omega$ ) [70]. The device shows a responsivity of $1.34 \mathrm{~A} / \mathrm{W}$ and a dark current of $400 \mathrm{nA}$ for $45 \mu \mathrm{m}$ diameter device. Bandwidth up to $16 \mathrm{GHz}$ can be achieved in a similar structure [71,72]. Yang et al. reported an edge-coupled strained InGaAs quantum wells high speed photodetector with 3-dB bandwidth more than $10 \mathrm{GHz}$, with a responsivity of $0.3 \mathrm{~A} / \mathrm{W}$ and dark current of $120 \mathrm{nA}$. [73]. Similar bandwidth performance has also been reported by the same research group on normal incident strain relaxed $\mathrm{In}_{0.7} \mathrm{Ga}_{0.3} \mathrm{As}$ photodetectors [58,74,75].

InGaAs/GaAsSb MQWs is another candidate for eSWIR detection on InP substrate. The type-II band alignment of InGaAs and $\mathrm{GaAsSb}$ forms a narrow effective bandgap and can extend the cut-off wavelength to more than $3 \mu \mathrm{m}[26,29,57]$. The dark current of these device is low at room temperature benefiting from the lattice-match properties [30]. The carrier transport in InGaAs/GaAsSb MQWs can be fast by properly designing the structure of MQWs [76,77]. Tossoun et al. demonstrated waveguide integrated InGaAs/GaAsSb MQWs waveguide photodetectors with 3-dB bandwidth of $3.5 \mathrm{GHz}$ and $10 \mathrm{GHz}[78,79]$. Since hole carrier escape time limits the transit time [77,79], eliminating the hole transport can potentially improve the 3-dB bandwidth [76]. Our group in ShanghaiTech University utilized uni-traveling carrier structure by incorporating InGaAs/GaAsSb MQWs as absorption layer and InP layer as drift layer, demonstrated a 3-dB bandwidth of $25 \mathrm{GHz}$ at 
$2 \mu \mathrm{m}$ with dark current of $5 \mathrm{nA}$ at room temperature under $-5 \mathrm{~V}$ [80]. The eye diagram up to $30 \mathrm{~Gb} / \mathrm{s}$ can be observed for the $10 \mu \mathrm{m}$ diameter devices. The schematics of the band diagram of the type-II MQWs based UTC photodiodes is shown in Figure 5.

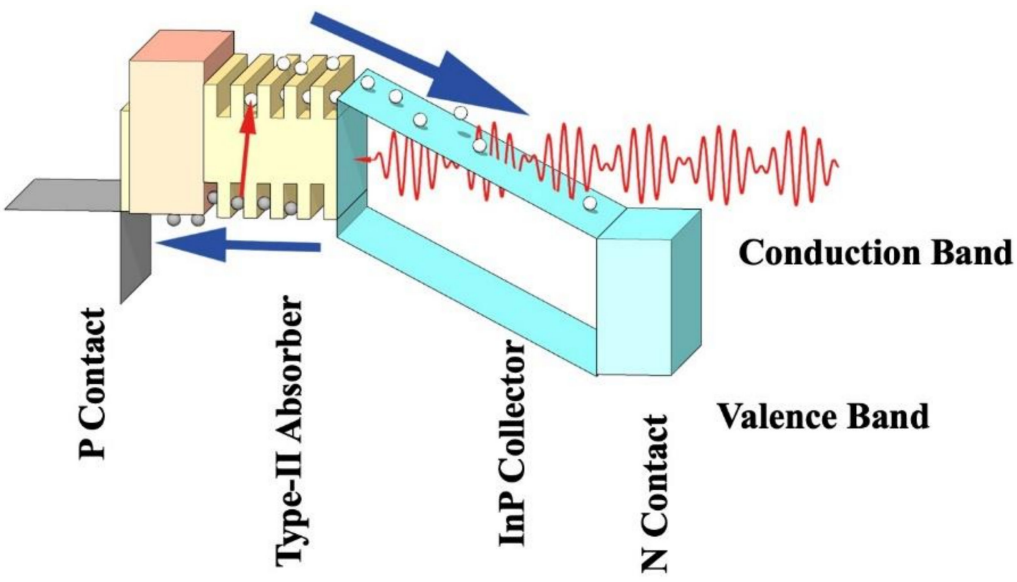

Figure 5. The schematics of the band diagram of the $2 \mu \mathrm{m}$ UTC photodiodes with type-II MQW as the absorber.

Quaternary compound InGaAsSb on GaSb substrate has a tunable bandgap ranging from 0.25 to $0.75 \mathrm{eV}$, and InGaAsSb photodetectors operating at around $2 \mu \mathrm{m}$ wavelength have been studied since the 1980s [81]. However, the growth and fabrication of $\mathrm{GaSb}$ based quanternary material is still challenging [82]. Early work shows that $160 \mathrm{ps}$ FWHM and 2 Gbit/s data rate is achievable on p-i-n photodetector with $3 \mu \mathrm{m}$ thick $\mathrm{In}_{0.18} \mathrm{Ga}_{0.82} \mathrm{As}_{0.17} \mathrm{Sb}_{0.83}$ absorption layer [83]. Andreev et al. reported a InGaAsSb p-i$\mathrm{n}$ photodetector with separated sensitive and contact mesa, achieving a bandwidth of $2-5 \mathrm{GHz}$ [84]. Wun et al. reported partially depleted $\mathrm{In}_{0.2} \mathrm{Ga}_{0.8} \mathrm{As}_{0.16} \mathrm{Sb}_{0.84}$ absorber $\mathrm{p}-\mathrm{i}-\mathrm{n}$ photodetector with $2.5 \mu \mathrm{m}$ cut-off wavelength and $6 \mathrm{GHz}$ operating frequency measured with $1.55 \mu \mathrm{m}$ light source [85]. The performances of eSWIR detector technologies mentioned in this subsection are summarized in Table 1 below.

Table 1. High speed photodetectors for eSWIR operation.

\begin{tabular}{|c|c|c|c|c|c|}
\hline Material and Structure & Cut-off Wavelength $(\mu \mathrm{m})$ & Responsivity (A/W) & Dark Current (or Density) & Response Speed & References \\
\hline GeSn MQWs on Si & 2.2 & 0.023 & $0.031 \mathrm{~A} / \mathrm{cm}^{2} @-1 \mathrm{~V}$ & $1.2 \mathrm{GHz}$ & [53] \\
\hline GeSn MQWs on $\mathrm{Si}$ & 2.05 & 0.015 & $0.044 \mathrm{~A} / \mathrm{cm}^{2} @-1 \mathrm{~V}$ & $10 \mathrm{GHz}$ & [54] \\
\hline GeSn on $\mathrm{Si}$ & 2.5 & $0.19 @ 1.55 \mu \mathrm{m}$ & & $1.78 \mathrm{GHz}$ & [55] \\
\hline Defect-mediated Si & $>2$ & 0.3 & $1 \mu \mathrm{A} @-30 \mathrm{~V}$ & $15 \mathrm{GHz}$ & [63] \\
\hline In-rich InGaAs on InP & $>2$ & 1.34 & $400 \mathrm{nA} @-5 \mathrm{~V}$ & $6 \mathrm{GHz}$ & [70] \\
\hline In-rich InGaAs on InP & 2.2 & 1.2 & $25 \mu \mathrm{A} @-5 \mathrm{~V}$ & $16 \mathrm{GHz}$ & [71] \\
\hline In-rich InGaAs on InP & $>2$ & 0.3 & 120 nA@-3V & $10 \mathrm{GHz}$ & [73] \\
\hline In-rich InGaAs on InP & $>2$ & 0.94 & $2 \mu \mathrm{A} @-5 \mathrm{~V}$ & $6 \mathrm{GHz}$ & [74] \\
\hline In-rich InGaAs on InP & $>2$ & 0.93 & $0.52 \mu \mathrm{A} @-5 \mathrm{~V}$ & $10 \mathrm{GHz}$ & [58] \\
\hline In-rich InGaAs on InP & $>2$ & 0.73 & $0.9 \mu \mathrm{A} @-2 \mathrm{~V}$ & $6 \mathrm{GHz}$ & [75] \\
\hline InGaAs/GaAsSb on InP & 2.4 & 0.35 & $12 \mathrm{~mA} / \mathrm{cm}^{2} @-5 \mathrm{~V}$ & $3.7 \mathrm{GHz}$ & [77] \\
\hline $\begin{array}{c}\text { InGaAs/GaAsSb on InP } \\
\text { waveguide PD }\end{array}$ & $>2.2$ & 0.27 & 100 nA @-2 V & $3.5 \mathrm{GHz}$ & [78] \\
\hline $\begin{array}{c}\text { InGaAs/GaAsSb on InP } \\
\text { waveguide PD }\end{array}$ & $>2$ & 0.84 & $1 \mathrm{nA} @-1 \mathrm{~V}$ & $10 \mathrm{GHz}$ & [79] \\
\hline InGaAs/GaAsSb on InP & 2.25 & 0.07 & $5 \mathrm{nA} @-5 \mathrm{~V}$ & $25 \mathrm{GHz}$ & [80] \\
\hline GaInAsSb on GaSb & 2.4 & 1.15 & $1.5 \mu \mathrm{A} @-3 \mathrm{~V}$ & $2-5 \mathrm{GHz}$ & [84] \\
\hline GaInAsSb on $\mathrm{GaSb}$ & 2.5 & $0.4 @ 1.55 \mu \mathrm{m}$ & $0.7 \mu \mathrm{A} @-2 \mathrm{~V}$ & $6 \mathrm{GHz}$ & [85] \\
\hline
\end{tabular}

\subsection{MWIR Operation}

Ternary compound $\mathrm{HgCdTe}$ (mercury cadmium telluride, MCT) is the most developed alloy material for MWIR and LWIR detection. The very small lattice mismatch between $\mathrm{HgTe}$ and CdTe make it possible to gradually tune the material bandgap, resulting in the 
cut-off wavelength ranging from 1 to $30 \mu \mathrm{m}$, and availability of high quality heterostructures [86]. Like other direct bandgap bulk material, $\mathrm{HgCdTe}$ can provide high quantum efficiency for infrared detection. At MWIR band, an $\mathrm{HgCdTe}$ avalanche photodetector has been developed with good performance [87]. With Cd composition lower than 0.5, the electron ionization coefficient of $\mathrm{HgCdTe}$ is significantly larger than hole ionization coefficient, which benefits the low noise avalanche photodiode at mid/long wavelength band and $1 \mathrm{GHz}$ bandwidth can be predicted [88]. Rothman et al. characterized the p-i-n $\mathrm{HgCdTe}$ avalanche photodiode with $145 \mathrm{MHz}$ bandwidth and $5.0 \mu \mathrm{m}$ cut-off wavelength at $77 \mathrm{~K}$ [89]. Perrais et al. reported a $600 \mathrm{MHz}$ RC-limited bandwidth HgCdTe avalanche diode with $5.2 \mu \mathrm{m}$ cut-off wavelength at $80 \mathrm{~K}$, and the transit time limited bandwidth is expected to be $15 \mathrm{GHz}$, leading to a gain bandwidth product of $3 \mathrm{THz}$ [90].

$\mathrm{InSb}$ is also another common material choice for MWIR detection. Ibrhim et al. reported an InSb p-i-n photodetector grown on semi-isolated GaAs substrate with a 3-dB bandwidth of $8.5 \mathrm{GHz}$ at room temperature with $2500 \mathrm{~nm}$ wavelength pulse light source. The devices exhibited a dark current level of $1-10 \mathrm{~mA}$ at $-0.5 \mathrm{~V}$ at $77 \mathrm{~K}$ for devices diameter ranging from 60 to $150 \mu \mathrm{m}$ [91].

Photovoltaic operation of QCD has made it possible to perform MWIR detection at room temperature, and also opened up possibility to achieve high response speed. The operation principle of QCD is based on inter-subband transitions in quantum wells embedded in an asymmetric, saw-tooth-like conduction band structure, which allows transport of the excited electrons in one direction only. The device can be operated with no bias, and thus no dark current. The sensitivity of the device can be improved by incorporating more stage of the cascade structure [92]. Hofstetter et al. reported a room temperature InP-based InGaAs/InAlAs QCD with 3-dB bandwidth of $4 \mathrm{GHz}$ and maximum modulation frequency of $23 \mathrm{GHz}$ at $5.35 \mu \mathrm{m}$ wavelength [93]. Zhou et al. reported a room temperature QCD with $9 \mathrm{GHz}$ bandwidth at $4.3 \mu \mathrm{m}$ [94]. Dougakiuchi et al. reported a $5 \mathrm{GHz}$ bandwidth QCD with radio frequency $(\mathrm{RF})$ response detectable at $26 \mathrm{GHz}$ [95]. Nevertheless, one disadvantage of these QCDs as well as QWIPs based on inter-subband transition, is that these devices require gratings for normal incidence detection. One way to overcome this drawback is to use quantum dots (QDs) instead of QWs for light absorption. QDs based QCD have been demonstrated with normal incidence response in MWIR and LWIR region [96-98]. However, the bandwidth of these QD-QCDs has not been reported so far.

The ICIP can be advantageous, in term of responsivity and sensitivity, over a QCD, because InAs/ $\mathrm{GaSb}$ absorber could offer high absorption efficiency and lower dark current due to the longer non-radiative carrier lifetime of the interband process. For high-speed operation, as discussed in the previous section, ICIP could also have particular advantages over single-stage detector similar to QCD due to the multiple-stage architecture. Lotfi et al. characterized the frequency response of interband cascade laser and detector system, where the extracted bandwidth of ICIP is $1.3 \mathrm{GHz}$ [99]. Later on, our group used a two-stage interband cascade photodetectors with total absorber thickness of $2400 \mathrm{~nm}$ to achieve a 3-dB bandwidth of $2.4 \mathrm{GHz}$ [100]. The 3-dB bandwidth of ICIP was further boosted to $7.04 \mathrm{GHz}$ with a five-stage configuration which has a total absorber thickness of $1200 \mathrm{~nm}$ [101]. For the two stage ICIP, the device showed a cutoff wavelength of $5.3 \mu \mathrm{m}$ at $300 \mathrm{~K}$. A peak responsivity of around $1.1 \mathrm{~A} / \mathrm{W}$ can be observed at $184 \mathrm{~K}$ at $4.1 \mu \mathrm{m}$ with dark current density of $10 \mathrm{~mA} / \mathrm{cm}^{2}$ at $-0.1 \mathrm{~V}$. The 3- $\mathrm{dB}$ bandwidth of the device was characterized by the $1550 \mathrm{~nm}$ light source at varied bias conditions and temperatures. It was found that the 3-dB bandwidth of device first increased with temperature $(<200 \mathrm{~K})$ and then exhibited a slight decrease as temperature further increased with a peak 3-dB bandwidth value of $2.6 \mathrm{GHz}$ at $200 \mathrm{~K}$ under reverse bias of $-5 \mathrm{~V}$. The previous explanations in [100] may not be precise as we attempt to explain here again. As the temperature decreases from $300 \mathrm{~K}$ to $200 \mathrm{~K}$, we attribute the bandwidth decrease to the reduction of the carrier diffusion coefficient and mobility with temperature. As temperature further decreases below $200 \mathrm{~K}$, the carrier lifetime will increase, thus the recombination process of the optical generated electrons and holes at the interfaces of adjacent stages (i.e., the interfaces of 
electron injector layer and hole injector) will slow down, which makes the 3-dB bandwidth of the device decrease with temperature. As a comparison, for QCD structure, since only transport of electrons will contribute to photocurrent, and there is no such recombination process at the interfaces between adjacent stages, QCD could be favorable over ICIP in terms of ultra-high-speed operation. Moreover, the five-stage ICIP structure demonstrated in ref. [101] has a 3-dB bandwidth of $7.04 \mathrm{GHz}$ with a thinner absorption region. It is also found that the device with a $20 \mu \mathrm{m}$ diameter would saturate as the photo current exceeds $80 \mu \mathrm{A}$ due to long carrier lifetime and current mismatch between stages, which indicates that these devices may not be able to be used in an optical heterodyne technique with a high power local oscillator as a mixer [102].

Uni-traveling carrier photodiodes based on InAs/GaSb T2SL have also been demonstrated by our group recently for the first time [103]. The UTC photodiode structure was originally used in $1550 \mathrm{~nm}$ band, and then for $2 \mu \mathrm{m}$ band application, both on InP substrate [80]. For MWIR operation, the UTC photodiode is based on GaSb substrate. In Ref. [103], graded p-doped InAs/GaSb T2SLs were used as absorption regions with a total thickness of $225 \mathrm{~nm}$, and 430nm undoped InAs/AlSb SLs were used as a collector layer. The device shows a 3-dB bandwidth of $6.58 \mathrm{GHz}$ at $300 \mathrm{~K}$. It is noted that UTC photodiodes can be used for high power application in the near infrared band, which indicates these MWIR UTC photodiodes may be potentially used in an optical heterodyne technique with a powerful local oscillator as well. However, the bandwidth of this first MWIR UTC device is lower than expected with such a thin absorber layer; the potential reason may be due to low mobility of InAs/GaSb and InAs/AlSb SLs especially in the carrier transport direction $[104,105]$.

The device performances of MWIR high-speed detector technologies mentioned in this subsection are summarized in Table 2 below.

Table 2. High speed photodetectors for MWIR operation.

\begin{tabular}{|c|c|c|c|c|c|}
\hline Material and Structure & Cut-off Wavelength $(\mu \mathrm{m})$ & Responsivity (A/W) & Dark Current (or Density) & Response Speed & References \\
\hline HgCdTe APD & 5 & & & $145 \mathrm{MHz}$ & [89] \\
\hline HgCdTe APD & 5.2 & & & $600 \mathrm{MHz}$ & [90] \\
\hline InSb on $\mathrm{GaAs}$ & 5.33 & $1.8 @ 77 \mathrm{~K}$ & & $8.5 \mathrm{GHz} @-2.5 \mathrm{~V}$ & [91] \\
\hline $\begin{array}{c}\text { InGaAs / InAlAs QCD } \\
\text { on InP }\end{array}$ & 5.35 & $0.0032 @ 100 \mathrm{~K}$ & & $4 \mathrm{GHz}$ & [93] \\
\hline $\begin{array}{c}\text { InGaAs / InAlAs QCD } \\
\text { on InP }\end{array}$ & $\sim 4.3$ & $0.0078 @ 300 \mathrm{~K}$ & & $9 \mathrm{GHz}$ & [94] \\
\hline QCD & $\sim 4.5$ & & & $5 \mathrm{GHz}$ & [95] \\
\hline ICIP on $\mathrm{GaSb}$ & 4.2 & $0.24 @ 300 \mathrm{~K}$ & & $1.3 \mathrm{GHz}$ & [99] \\
\hline ICIP on InAs & 5.3 & $0.1 @ 300 \mathrm{~K}$ & $3.97 \mathrm{~A} / \mathrm{cm}^{2} @-0.1 \mathrm{~V}$ & $2.4 \mathrm{GHz}$ & [100] \\
\hline ICIP on InAs & 5 & $0.067 @ 300 \mathrm{~K}$ & $0.094 \mathrm{~A} / \mathrm{cm}^{2} @-0.1 \mathrm{~V}$ & $7.04 \mathrm{GHz}$ & [101] \\
\hline InAs/GaSb UTC on GaSb & 5.6 & $0.1 @ 300 \mathrm{~K}$ & $0.6 \mathrm{~A} / \mathrm{cm}^{2} @-0.5 \mathrm{~V}$ & $6.58 \mathrm{GHz}$ & [103] \\
\hline
\end{tabular}

\subsection{LWIR Operation}

For LWIR band, high performance HgCdTe photodiodes with more than $30 \%$ QE and $1 \mathrm{GHz}$ bandwidth have been achieved in cryogenic temperature (77 K) [106,107]. For high temperature $(>200 \mathrm{~K})$ operation and room temperature $(300 \mathrm{~K})$ operation, Auger recombination is a main factor that limits the detectivity of the infrared photodetector. By optimizing composition and doping level, the Auger process can be partially suppressed [108]. Zero/low bias is also proposed for noise reduction. Researchers have predicted LWIR HgCdTe photodiodes with tens of picosecond response times at $230 \mathrm{~K}$ temperature at low bias [109] and zero bias [110] with p-type HgCdTe, which could enjoy the high electron diffusion coefficient.

GaAs-based QWIP is expected to have a fast frequency response due to the short intrinsic carrier lifetime [35]. The typical lifetime of excited carriers is of the order of a few picoseconds [35], which enables QWIP not only for high-speed operation but also very high saturation intensity [111]. These properties make QWIP advantageous for a heterodyne detection scheme where a high-power local oscillator can used to drive a high photocurrent 
that can coherently mix with a signal shifted in frequency with respect to the local oscillator, which is typically unobtainable in interband-based photodetectors such as ICIP [101] due to much longer carrier lifetime. QWIP was characterized with $10.2 \mu \mathrm{m} \mathrm{CO}$ laser for coherent detection, showing a 3-dB bandwidth of $1.5 \mathrm{GHz}$ for $150 \mu \mathrm{m}$ device and $8 \mathrm{GHz}$ for a $75 \mu \mathrm{m}$ device at $77 \mathrm{~K}$, and the intrinsic bandwidth was estimated to be $64 \mathrm{GHz}$ [112]. Liu et al. then demonstrated QWIP heterodyne detection of $26.5 \mathrm{GHz}$ with 3-dB bandwidth of

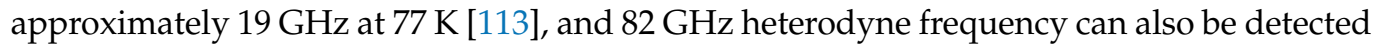
by down conversion using QWIP as a microwave mixer [114]. Grant et al. demonstrated a QWIP and measured the heterodyne output signal up to $75 \mathrm{GHz}$ at $100 \mathrm{~K}$ [115]. The frequency response can be even detected up to $110 \mathrm{GHz}$ at $300 \mathrm{~K}$ temperature, and the mechanisms affecting the frequency response were studied [116]. Room temperature QWIPs with heterodyne detection of $4 \mathrm{GHz}$ and $26 \mathrm{GHz}$ at $9 \mu \mathrm{m}$ and $4.6 \mu \mathrm{m}$ respectively, are achieved by incorporating metamaterial made of sub-wavelength microcavity to enhance the responsivity and suppress the dark current $[117,118]$. A similar patch-antenna was used for QCD structure with room temperature responsivity of $50 \mathrm{~mA} / \mathrm{W}$ at $0 \mathrm{~V}$ bias, and a $1.4 \mathrm{GHz}$ electrical bandwidth [119].

The device performances of the LWIR high-speed detector technologies mentioned in this subsection are summarized in Table 3 below.

Table 3. High speed photodetectors for LWIR operation.

\begin{tabular}{|c|c|c|c|c|c|}
\hline $\begin{array}{c}\text { Material } \\
\text { and Structure }\end{array}$ & $\begin{array}{c}\text { Operation } \\
\text { Wavelength }(\mu \mathrm{m})\end{array}$ & $\begin{array}{c}\text { Responsivity or } \\
\text { Quantum Efficiency }\end{array}$ & $\begin{array}{l}\text { Dark Current } \\
\text { (or Density) }\end{array}$ & Response Speed & References \\
\hline HgCdTe p-i-n & 10 & Around $30 \%$ & & $1 \mathrm{GHz} @ 77 \mathrm{~K}$ & [106] \\
\hline QWIP on GaAs & 10 & $11 \%$ & & 8 GHz@77 K & [112] \\
\hline QWIP on GaAs & 9.3 & $0.45 \mathrm{~A} / \mathrm{W}$ & & 19 GHz@ 92 K & [113] \\
\hline QWIP on GaAs & 9 & & & 75 GHz @ $100 \mathrm{~K}$ & [115] \\
\hline QWIP on GaAs & 9 & $0.2 \mathrm{~A} / \mathrm{W}$ & $3.5 \mathrm{~mA} @ 0.5 \mathrm{~V}$ & 4 GHz@300 K & [117] \\
\hline QCD on GaAs & 9 & 50 mA/W@0 V & & 1.4 GHz @ 295 K & [119] \\
\hline
\end{tabular}

\section{Challenges and Perspectives}

For high speed operation in wavelength range beyond $1.7 \mu \mathrm{m}$, there are a number of challenges given the current development situation. In this section, both the challenges and perspectives of the high speed eSWIR/MWIR/LWIR photodetectors will be discussed.

\subsection{Bandwidth Characterization}

First, the bandwidth characterization of the photodetector in the eSWIR/MWIR/LWIR wavelength band is not straightforward. For a photodetector operating at telecom band, a high-speed modulator is commercially available, which can generate high speed optical signal and make the bandwidth characterization in a relatively simple way. However, in the MWIR and LWIR band, high speed modulators are not available in the MWIR and LWIR band, and some other methods have to be used to get around this issue.

One way to test the MWIR and LWIR device is still using $1550 \mathrm{~nm}$ high speed light source setup along with vector network analyzer (VNA) or Lightwave Component Analyzer (LCA) as shown in Figure 6. This setup can only be used to estimate the bandwidth of MWIR/LWIR devices based on interband transition, but not for device based on intersubband transition such as QCDs and QWIPs, since inter-subband transition devices only have relatively narrow optical responses at the targeted wavelength and usually have no response at $1550 \mathrm{~nm}$ wavelength. Moreover, using $1550 \mathrm{~nm}$ wavelength could cause strong absorption at the surface of device given the large absorption coefficient at $1550 \mathrm{~nm}$. That could under-estimate the $3-\mathrm{dB}$ bandwidth of the devices. 


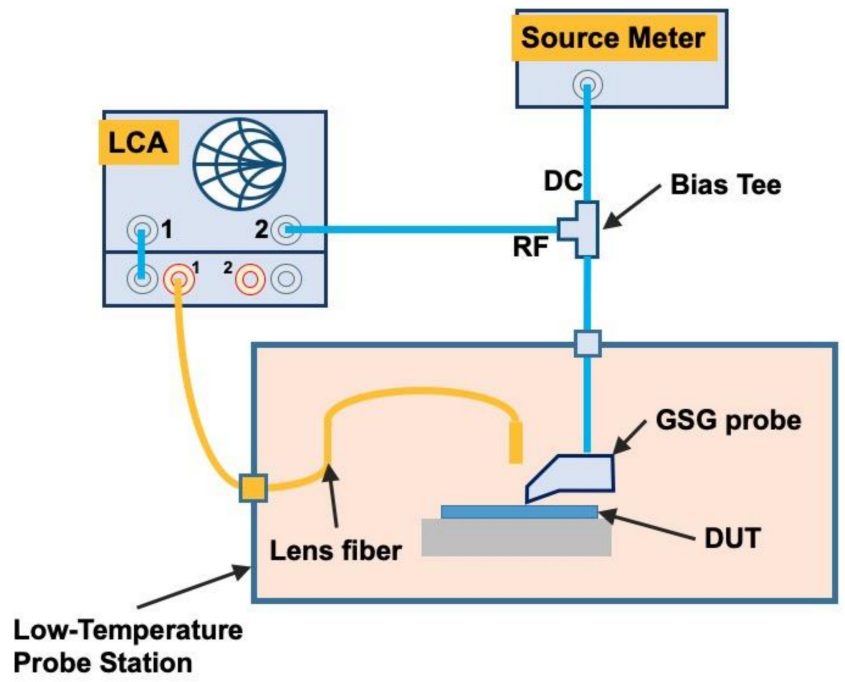

Figure 6. Bandwidth characterization of high-speed photodetector with Lightwave Component Analyzer (LCA).

Another way to measure the frequency response of photodetector is based on the frequency-swept modulated optical signal with a tunable heterodyne setup, as shown in Figure 7. The heterodyne setup uses two single mode distributed feedback (DFB) lasers with slightly different wavelengths to generate an optical signal with a different frequency. By sweeping the frequency of the signal, which is achieved by changing the temperature and thus the wavelength of one DFB laser, the bandwidth of the photodetectors can be characterized. At a wavelength around $2 \mu \mathrm{m}$, fiber couple output DFB lasers can be implemented along with an optical coupler, which could simplify the optical alignment. However, in the MWIR and LWIR band, free space optical alignment of two QCL DFB lasers would be much more challenging.

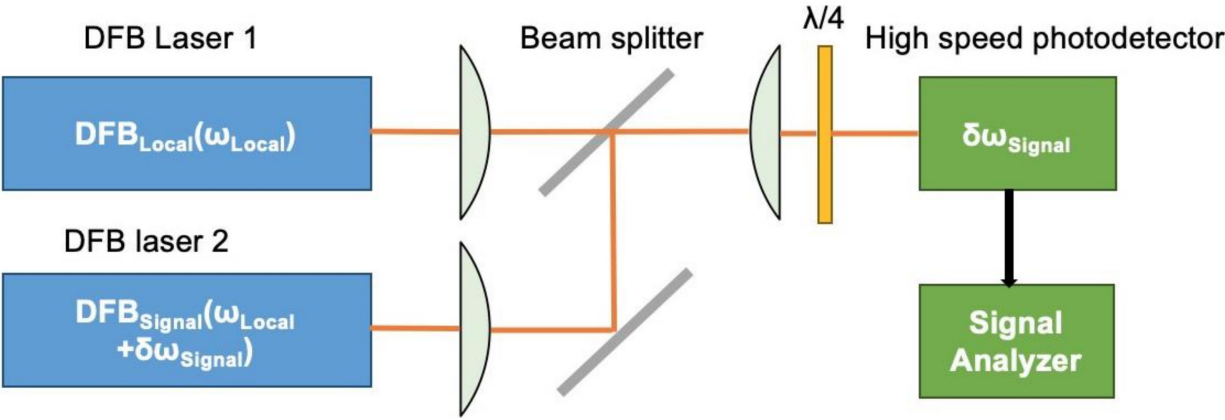

Figure 7. The tunable heterodyne setup schematics for bandwidth characterization of highspeed photodetectors.

The third approach of characterizing the device speed is using an optical short-pulse signal in the MWIR and LWIR region, based on an optical parametric oscillator. The temporal response of the devices can be recorded with a high-speed oscilloscope with the devices exposed by optical pulses. Then the bandwidth of the devices can be further calculated through Fourier transform of the electrical pulse signal.

For QWIPs and QCDs structure, microwave rectification techniques utilizing an RF launcher have also been used to evaluate the excited-electron lifetime and device bandwidth [43]. Due to the inherent nonlinear I-V characteristics of QWIPs and QCDs, a microwave rectification technique is a way to study the roll-off behavior of the device by applying an RF signal to the device and measuring the variation of its DC biasing current. Since it takes the same time period of about excited-electron lifetime for the system to re-establish its equilibrium under perturbation by either external applied bias or infrared 
excitation, the excited-electron lifetime can be inferred from microwave rectification [43]. The setup of microwave rectification techniques is shown in Figure 8. This method reflects the frequency response of devices in an indirect way.

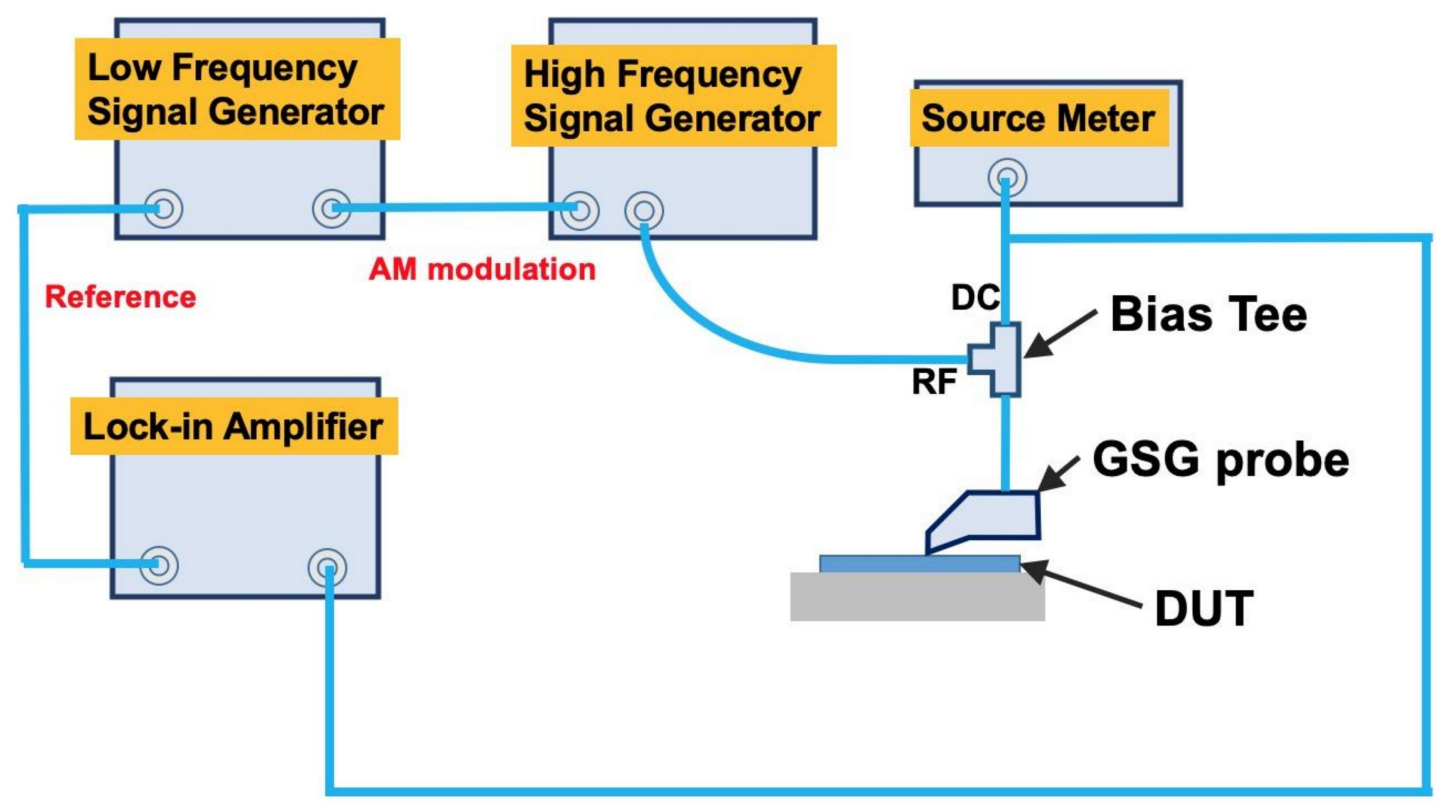

Figure 8. The schematics of the microwave rectification setup.

\subsection{Design Challenges}

Besides the RF characterization difficulties for longer wavelength devices, another major challenge for high speed detectors is to achieve devices with high bandwidth, low dark current, and high quantum efficiency simultaneously. For high-speed operation, usually an external bias is needed to accelerate the carrier transport and increase the device bandwidth. However, this will inevitably cause higher dark current due to the strong dependences of tunneling current and surface leakage current on bias. Furthermore, for the recent photodetector work based on InAs/GaSb, InAs/InAsSb T2SLs, a p-doped absorber is often desirable for high speed operation, since electrons, as the minority carriers in $\mathrm{p}$ doped absorber, have higher mobility and smaller effective mass than holes. However, the Fermi-level pining at the surface in p-doped T2SLs creates an additional electron leakage path in the surface, which could cause significant surface leakage. Surface passivation and a mesa etch process need to be carefully optimized for these devices. Barrier devices such as ICIP could potentially solve this issue, due to the multiple electron barriers and hole barriers in the structure, which can block the surface leakage path. Moreover, InAs/GaSb, InAs/InAsSb T2SLs are typically grown on InAs or GaSb substrate. Nevertheless, high quality semi-insulated InAs or GaSb substrate is not available, and the current n-type substrate is lossy for RF signal extraction which could be another limiting factor for highspeed operation. GaAs or InP-based devices such as QWIPs and QCDs would not suffer from this issue, given the mature development of semi-insulated GaAs and InP substrate. Growth of InAs/GaSb T2SL or other MWIR/LWIR materials on semi-insulated GaAs substrate with buffer layer may be one of the solutions to achieve high RF performance, but the defects caused by lattice mismatch between active layers and substrate could cause high dark current [120-122].

\subsection{Perspectives}

Given the potential challenges of achieving high speed photodetectors in the eSWIR, MWIR, and LWIR region, it is still at an early stage of development. Better devices performance could be expected with continuous development of III-V material growth, 
process techniques, and device structure innovations. Moreover, new emerging materials such as colloidal QDs, graphene and transition-metal dichalcogenides (TMDCs) have recently appeared which show promise for low-cost optoelectronics applications [123-128]. These materials could be integrated with other materials without constraint of crystal lattice matching. Recently, high-speed and high responsivity vertical $\mathrm{MoTe}_{2}$-grahene van der Waals heterostructure photodetectors have been demonstrated at telecom Oband wavelength range with 3-dB bandwidth of $50 \mathrm{GHz}$ [128]. These devices enjoy the high carrier mobility of graphene to ensure fast carrier extraction and low contact resistance. Although most of the 2D material based high-speed detectors were reported at a telecom band, it is quite promising to extend the wavelength beyond $1.7 \mu \mathrm{m}$ for high speed operation by choosing different 2D materials [129].

\section{Conclusions}

In this paper, the RF characteristics of infrared photodetectors in the eSWIR, MWIR, and LWIR wavelength band along with other figures of merit are reviewed. For longer wavelength photodetection, the challenges presented in device characterization, as well as the demands for high speed, low dark current, and high responsivity, are discussed. The emerging quantum structures such as T2SL, QCD, and ICIP, show prospect for room temperature operation of MWIR/LWIR detection, and may potentially be used in future free space optical communication, frequency comb spectroscopy, and some other emerging areas requiring high speed receivers.

Author Contributions: B.C., Y.C. and Z.D. contributed to the writing of the manuscript. All authors have read and agreed to the published version of the manuscript.

Funding: This research was funded by National Key Research and Development Program of China, grant number 2018YFB2201000; National Natural Science Foundation of China, grant number 61975121; Strategic Priority Research Program of Chinese Academy of Sciences, grant number XDA18010000 and ShanghaiTech University startup funding, grant number F-0203-16-002.

Conflicts of Interest: The authors declare no conflict of interest.

\section{References}

1. Ellis, A.D.; Zhao, J.; Cotter, D. Approaching the Non-Linear Shannon Limit. J. Lightwave Technol. 2010, 28, 423-433. [CrossRef]

2. Roberts, P.J.; Couny, F.; Sabert, H.; Mangan, B.J.; Williams, D.P.; Farr, L.; Mason, M.W.; Tomlinson, A.; Birks, T.A.; Knight, J.C.A. Ultimate low loss of hollow-core photonic crystal fibres. Opt. Express 2005, 13, 236. [CrossRef] [PubMed]

3. Li, Z.; Heidt, A.; Simakov, N.; Jung, Y.; Daniel, J.; Alam, S.; Richardson, D. Diode-pumped wideband thulium-doped fiber amplifiers for optical communications in the 1800-2050 nm window. Opt. Express 2013, 21, 26450-26455. [CrossRef] [PubMed]

4. Petrovich, M.N.; Poletti, F.; Wooler, J.; Heidt, A.; Baddela, N.K.; Li, Z.; Gray, D.R.; Slavk, R.; Parmigiani, F.; Wheeler, N.; et al. First Demonstration of $2 \mu \mathrm{m}$ Data Transmission in a Low-Loss Hollow Core Photonic Bandgap Fiber. In Proceedings of the European Conference and Exhibition on Optical Communication (ECOC), Amsterdam, The Netherlands, 16-20 September 2012. [CrossRef]

5. Mac Suibhne, N.; Li, Z.; Baeuerle, B.; Zhao, J.; Wooler, J.P.; Alam, S.U.; Poletti, F.; Petrovich, M.N.; Heidt, A.M.; Wheeler, N.V.; et al. WDM transmission at $2 \mu \mathrm{m}$ over low-loss Hollow Core Photonic Bandgap Fiber. In Proceedings of the Optical Fiber Communication Conference and Exposition and the National Fiber Optic Engineers Conference (OFC/NFOEC), Anaheim, CA, USA, 17-21 March 2013; pp. 1-3.

6. Petrovich, M.N.; Poletti, F.; Wooler, J.P.; Heidt, A.M.; Baddela, N.K.; Li, Z.; Gray, D.R.; Slavk, R.; Parmigiani, F.; Wheeler, N.V.; et al. Demonstration of amplified data transmission at $2 \mu \mathrm{m}$ in a low-loss wide bandwidth hollow core photonic bandgap fiber. Opt. Express 2013, 21, 28559. [CrossRef]

7. Zhang, H.; Kavanagh, N.; Li, Z.; Zhao, J.; Ye, N.; Chen, Y.; Wheeler, N.V.; Wooler, J.P.; Hayes, J.R.; Sandoghchi, S.R.; et al. $100 \mathrm{Gbit} / \mathrm{s}$ WDM transmission at $2 \mu \mathrm{m}$ : Transmission studies in both low-loss hollow core photonic bandgap fiber and solid core fiber. Opt. Express 2015, 23, 4946. [CrossRef]

8. Shen, W.; Du, J.; Sun, L.; Wang, C.; Zhu, Y.; Xu, K.; Chen, B.; He, Z. Low-Latency and High-Speed Hollow-Core Fiber Optical Interconnection at 2-Micron Waveband. J. Lightwave Technol. 2020, 38, 3874-3882. [CrossRef]

9. Henniger, H.; Wilfert, O. An introduction to free-space optical communications. Radioengineering 2010, 19, $203-212$.

10. Chan, V.W. Free-space optical communications. J. Lightwave Technol. 2006, 24, 4750-4762. [CrossRef]

11. Manor, H.; Arnon, S. Performance of an optical wireless communication system as a function of wavelength. Appl. Opt. 2003, 42, 4285-4294. [CrossRef] 
12. Khalighi, M.A.; Uysal, M. Survey on Free Space Optical Communication: A Communication Theory Perspective. IEEE Commun. Surv. Tutor. 2014, 16, 2231-2258. [CrossRef]

13. Schiller, S. Spectrometry with frequency combs. Opt. Lett. 2002, 27, 766-768. [CrossRef] [PubMed]

14. Picqué, N.; Hänsch, T.W. Frequency comb spectroscopy. Nat. Photonics 2019, 13, 146-157. [CrossRef]

15. Ambrico, P.F.; Amodeo, A.; Di Girolamo, P.; Spinelli, N. Sensitivity analysis of differential absorption lidar measurements in the mid-infrared region. Appl. Opt. 2000, 39, 6847-6865. [CrossRef]

16. Lambert-Girard, S.; Allard, M.; Piché, M.; Babin, F. Differential optical absorption spectroscopy lidar for mid-infrared gaseous measurements. Appl. Opt. 2015, 54, 1647-1656. [CrossRef]

17. Judd, K.M.; Thornton, M.P.; Richards, A.A. Automotive sensing: Assessing the impact of fog on LWIR, MWIR, SWIR, visible, and lidar performance. In Proceedings of the Infrared Technology and Applications XLV, Baltimore, MD, USA, 14-18 April 2019; p. $110021 \mathrm{~F}$.

18. Thornton, M.P.; Judd, K.M.; Richards, A.A.; Redman, B.J. Multispectral short-range imaging through artificial fog. In Proceedings of the Infrared Imaging Systems: Design, Analysis, Modeling, and Testing XXX, Baltimore, MD, USA, 16-18 April 2019 ; p. 110010Z.

19. Kopytko, M.; Rogalski, A. HgCdTe barrier infrared detectors. Prog. Quantum Electron. 2016, 47, 1-18. [CrossRef]

20. Rogalski, A. Recent progress in infrared detector technologies. Infrared Phys. Technol. 2011, 54, 136-154. [CrossRef]

21. Norton, P. HgCdTe infrared detectors. Optoelectron. Rev. 2002, 3, 159-174.

22. Rogalski, A.; Martyniuk, P.; Kopytko, M. InAs/GaSb type-II superlattice infrared detectors: Future prospect. Appl. Phys. Rev. 2017, 4, 031304. [CrossRef]

23. Rodriguez, J.-B.; Plis, E.; Bishop, G.; Sharma, Y.; Kim, H.; Dawson, L.; Krishna, S. nBn structure based on In As/Ga Sb type-II strained layer superlattices. Appl. Phys. Lett. 2007, 91, 043514. [CrossRef]

24. Ting, D.Z.; Rafol, S.B.; Khoshakhlagh, A.; Soibel, A.; Keo, S.A.; Fisher, A.M.; Pepper, B.J.; Hill, C.J.; Gunapala, S.D. InAs/InAsSb Type-II Strained-Layer Superlattice Infrared Photodetectors. Micromachines 2020, 11, 958. [CrossRef]

25. Steenbergen, E.; Connelly, B.; Metcalfe, G.; Shen, H.; Wraback, M.; Lubyshev, D.; Qiu, Y.; Fastenau, J.; Liu, A.; Elhamri, S. Significantly improved minority carrier lifetime observed in a long-wavelength infrared III-V type-II superlattice comprised of InAs/InAsSb. Appl. Phys. Lett. 2011, 99, 251110. [CrossRef]

26. Chen, B.; Jiang, W.; Yuan, J.; Holmes, A.L.; Onat, B.M. SWIR/MWIR InP-based pin photodiodes with InGaAs/GaAsSb type-II quantum wells. IEEE J. Quantum Electron. 2011, 47, 1244-1250. [CrossRef]

27. Chen, B.; Holmes, A.L. InP-based short-wave infrared and midwave infrared photodiodes using a novel type-II straincompensated quantum well absorption region. Opt. Lett. 2013, 38, 2750-2753. [CrossRef] [PubMed]

28. Xie, Z.; Deng, Z.; Zou, X.; Chen, B. InP-Based Near Infrared/Extended-Short Wave Infrared Dual-Band Photodetector. IEEE Photonics Technol. Lett. 2020, 32, 1003-1006. [CrossRef]

29. Chen, B.; Jiang, W.; Holmes, A. Design of strain compensated InGaAs/GaAsSb type-II quantum well structures for mid-infrared photodiodes. Opt. Quantum Electron. 2012, 44, 103-109. [CrossRef]

30. Chen, B.; Yuan, J.; Holmes, A. Dark current modeling of InP based SWIR and MWIR InGaAs/GaAsSb type-II MQW photodiodes. Opt. Quantum Electron. 2013, 45, 271-277. [CrossRef]

31. Levine, B. Quantum-well infrared photodetectors. J. Appl. Phys. 1993, 74, R1-R81. [CrossRef]

32. Martyniuk, P.; Antoszewski, J.; Martyniuk, M.; Faraone, L.; Rogalski, A. New concepts in infrared photodetector designs. Appl. Phys. Rev. 2014, 1, 041102. [CrossRef]

33. Tsai, K.; Chang, K.; Lee, C.; Huang, K.-F.; Tsang, J.; Chen, H. Two-color infrared photodetector using GaAs/AlGaAs and strained InGaAs/AlGaAs multiquantum wells. Appl. Phys. Lett. 1993, 62, 3504-3506. [CrossRef]

34. Schneider, H.; Liu, H.C. Quantum Well Infrared Photodetectors; Springer: Berlin/Heidelberg, Germany, 2007.

35. Ehret, S.; Schneider, H.; Fleissner, J.; Koidl, P.; Böhm, G. Ultrafast intersubband photocurrent response in quantum-well infrared photodetectors. Appl. Phys. Lett. 1997, 71, 641-643. [CrossRef]

36. Ryzhii, V. The theory of quantum-dot infrared phototransistors. Semicond. Sci. Technol. 1996, 11, 759-765. [CrossRef]

37. Jiang, J.; Tsao, S.; O'Sullivan, T.; Zhang, W.; Lim, H.; Sills, T.; Mi, K.; Razeghi, M.; Brown, G.; Tidrow, M. High detectivity InGaAs/InGaP quantum-dot infrared photodetectors grown by low pressure metalorganic chemical vapor deposition. Appl. Phys. Lett. 2004, 84, 2166-2168. [CrossRef]

38. Venghaus, H.; Grote, N. Fibre Optic Communication: Key Devices; Springer: Berlin/Heidelberg, Germany, 2017 ; Volume 161.

39. Kato, K.; Hata, S.; Kawano, K.; Kozen, A. Design of ultrawide-band, high-sensitivity pin protodetectors. IEICE Trans. Electron. 1993, 76, 214-221.

40. Effenberger, F.J.; Joshi, A.M. Ultrafast, dual-depletion region, InGaAs/InP pin detector. J. Lightwave Technol. 1996, 14, 1859-1864. [CrossRef]

41. Ito, H.; Furuta, T.; Kodama, S.; Ishibashi, T. InP/InGaAs uni-travelling-carrier photodiode with $310 \mathrm{GHz}$ bandwidth. Electron. Lett. 2000, 36, 1809-1810. [CrossRef]

42. Liu, H.C. Dependence of absorption spectrum and responsivity on the upper state position in quantum well intersubband photodetectors. J. Appl. Phys. 1993, 73, 3062-3067. [CrossRef]

43. Liu, H.; Li, J.; Buchanan, M.; Wasilewski, Z. High-frequency quantum-well infrared photodetectors measured by microwaverectification technique. IEEE J. Quantum Electron. 1996, 32, 1024-1028. [CrossRef] 
44. Gendron, L.; Carras, M.; Huynh, A.; Ortiz, V.; Koeniguer, C.; Berger, V. Quantum cascade photodetector. Appl. Phys. Lett. 2004, 85, 2824-2826. [CrossRef]

45. Yang, R.Q.; Tian, Z.; Cai, Z.; Klem, J.; Johnson, M.B.; Liu, H. Interband-cascade infrared photodetectors with superlattice absorbers. J. Appl. Phys. 2010, 107, 054514. [CrossRef]

46. Huang, W.; Rassel, S.S.; Li, L.; Massengale, J.A.; Yang, R.Q.; Mishima, T.D.; Santos, M.B. A unified figure of merit for interband and intersubband cascade devices. Infrared Phys. Technol. 2019, 96, 298-302. [CrossRef]

47. Hinkey, R.T.; Yang, R.Q. Theory of multiple-stage interband photovoltaic devices and ultimate performance limit comparison of multiple-stage and single-stage interband infrared detectors. J. Appl. Phys. 2013, 114, 104506. [CrossRef]

48. Jutzi, M.; Berroth, M.; Wohl, G.; Oehme, M.; Kasper, E. Ge-on-Si vertical incidence photodiodes with 39-GHz bandwidth. IEEE Photonics Technol. Lett. 2005, 17, 1510-1512. [CrossRef]

49. Masini, C.; Calace, L.; Assanto, G.; Luan, H.-C.; Kimerling, L.C. High-performance pin Ge on Si photodetectors for the near infrared: From model to demonstration. IEEE Trans. Electron Device 2001, 48, 1092-1096. [CrossRef]

50. Michel, J.; Liu, J.; Kimerling, L.C. High-performance Ge-on-Si photodetectors. Nat. Photonics 2010, 4, 527-534. [CrossRef]

51. Gassenq, A.; Gencarelli, F.; van Campenhout, J.; Shimura, Y.; Loo, R.; Narcy, G.; Vincent, B.; Roelkens, G. GeSn/Ge heterostructure short-wave infrared photodetectors on silicon. Opt. Express 2012, 20, 27297. [CrossRef]

52. Cong, H.; Xue, C.; Zheng, J.; Yang, F.; Yu, K.; Liu, Z.; Zhang, X.; Cheng, B.; Wang, Q. Silicon Based GeSn p-i-n Photodetector for SWIR Detection. IEEE Photonics J. 2016, 8, 1-6. [CrossRef]

53. Dong, Y.; Wang, W.; Xu, S.; Lei, D.; Gong, X.; Guo, X.; Wang, H.; Lee, S.-Y.; Loke, W.-K.; Yoon, S.-F.; et al. Two-micron-wavelength germanium-tin photodiodes with low dark current and gigahertz bandwidth. Opt. Express 2017, 25, 15818-15827. [CrossRef]

54. Xu, S.; Wang, W.; Huang, Y.-C.; Dong, Y.; Masudy-Panah, S.; Wang, H.; Gong, X.; Yeo, Y.-C. High-speed photo detection at two-micron-wavelength: Technology enablement by GeSn/Ge multiple-quantum-well photodiode on $300 \mathrm{~mm}$ Si substrate. Opt. Express 2019, 27, 5798. [CrossRef]

55. Tran, H.; Littlejohns, C.G.; Thomson, D.J.; Pham, T.; Ghetmiri, A.; Mosleh, A.; Margetis, J.; Tolle, J.; Mashanovich, G.; Du, W. Study of GeSn mid-infrared photodetectors for high frequency applications. Front. Mater. 2019, 6, 278. [CrossRef]

56. Zhou, H.; Xu, S.; Lin, Y.; Huang, Y.-C.; Son, B.; Chen, Q.; Guo, X.; Lee, K.H.; Goh, S.C.-K.; Gong, X.; et al. High-efficiency GeSn/Ge multiple-quantum-well photodetectors with photon-trapping microstructures operating at $2 \mu \mathrm{m}$. Opt. Express 2020, 28, 10280. [CrossRef]

57. Sidhu, R.; Duan, N.; Campbell, J.C.; Holmes, A.L. A long-wavelength photodiode on InP using lattice-matched GaInAs-GaAsSb type-II quantum wells. IEEE Photonics Technol. Lett. 2005, 17, 2715-2717. [CrossRef]

58. Ye, N.; Yang, H.; Gleeson, M.; Pavarelli, N.; Zhang, H.; O'Callaghan, J.; Han, W.; Nudds, N.; Collins, S.; Gocalinska, A. InGaAs Surface Normal Photodiode for 2 Optical Communication Systems. IEEE Photonics Technol. Lett. 2015, 27, $1469-1472$.

59. Geis, M.W.; Spector, S.J.; Grein, M.E.; Schulein, R.T.; Yoon, J.U.; Lennon, D.M.; Deneault, S.; Gan, F.; Kaertner, F.X.; Lyszczarz, T.M. CMOS-Compatible All-Si High-Speed Waveguide Photodiodes with High Responsivity in Near-Infrared Communication Band. IEEE Photonics Technol. Lett. 2007, 19, 152-154. [CrossRef]

60. Geis, M.W.; Spector, S.J.; Grein, M.E.; Yoon, J.U.; Lennon, D.M.; Lyszczarz, T.M. Silicon waveguide infrared photodiodes with $>35 \mathrm{GHz}$ bandwidth and phototransistors with $50 \mathrm{AW}^{-1}$ response. Opt. Express 2009, 17, 5193-5204. [CrossRef] [PubMed]

61. Grote, R.R.; Padmaraju, K.; Souhan, B.; Driscoll, J.B.; Bergman, K.; Osgood, R.M. 10 Gb/s Error-Free Operation of All-Silicon Ion-Implanted-Waveguide Photodiodes at $1.55 \mu \mathrm{m}$. IEEE Photonics Technol. Lett. 2013, 25, 67-70. [CrossRef]

62. Brian, S.; Richard, R.G.; Christine, P.C.; Hsu-Cheng, H.; Jeffrey, B.D.; Ming, L.; Aaron, S.; Hassaram, B.; Keren, B.; William, M.J.G.; et al. $\mathrm{Si}^{+}$-implanted Si-wire waveguide photodetectors for the mid-infrared. Opt. Express 2014, 22, 27415-27424. [CrossRef]

63. Ackert, J.J.; Thomson, D.J.; Shen, L.; Peacock, A.C.; Jessop, P.E.; Reed, G.T.; Mashanovich, G.Z.; Knights, A.P. High-speed detection at two micrometres with monolithic silicon photodiodes. Nat. Photonics 2015, 9, 393. [CrossRef]

64. Bowers, J.; Burrus, C. Ultrawide-band long-wavelength pin photodetectors. J. Lightwave Technol. 1987, 5, 1339-1350. [CrossRef]

65. Beling, A.; Campbell, J.C. InP-based high-speed photodetectors. J. Lightwave Technol. 2009, 27, 343-355. [CrossRef]

66. Makita, K.; Torikai, T.; Ishihara, H.; Taguchi, K. Ga1 - yInyAs/InAsxP1 - x $(y>0.53, x>0)$ pin photodiodes for long wavelength regions $(\lambda>2 \mu \mathrm{m})$ grown by hydride vapour phase epitaxy. Electron. Lett. 1988, 24, 379-380. [CrossRef]

67. Martinelli, R.U.; Zamerowski, T.J.; Longeway, P.A. $2.6 \mu \mathrm{m}$ InGaAs photodiodes. Appl. Phys. Lett. 1988, 53, 989-991. [CrossRef]

68. Li, C.; Zhang, Y.; Wang, K.; Gu, Y.; Li, H.; Li, Y. Distinction investigation of InGaAs photodetectors cutoff at 2.9 um. Infrared Phys. Technol. 2010, 53, 173-176. [CrossRef]

69. D'Hondt, M.; Moerman, I.; van Daele, P.; Demeester, P. Influence of buffer layer and processing on the dark current of 2.5 $\mu \mathrm{m}$-wavelength 2\%-mismatched InGaAs photodetectors. IEE Proc. Optoelectron. 1997, 144, 277-282.

70. Joshi, A.; Becker, D. High-speed low-noise p-i-n InGaAs photoreceiver at $2 \mu \mathrm{m}$. IEEE Photonics Technol. Lett. 2008, 20, 551-553. [CrossRef]

71. Joshi, A.; Datta, S. High-speed, large-area, p-i-n InGaAs photodiode linear array at 2-micron wavelength. In Proceedings of the Infrared Technology and Applications XXXVIII, Baltimore, MD, USA, 23-27 April 2012; p. 83533D. [CrossRef]

72. Joshi, A. Developments in high performance photodiodes. In Proceedings of the 2012 IEEE Photonics Conference, IPC 2012, Burlingame, CA, USA, 23-27 September 2012; pp. 1-2. [CrossRef] 
73. Yang, H.; Kelly, B.; Han, W.; Gunning, F.; Corbett, B.; Phelan, R.; O'Carroll, J.; Yang, H.; Peters, F.H.; Wang, X.; et al. Butterfly packaged high-speed and low leakage InGaAs quantum well photodiode for $2000 \mathrm{~nm}$ wavelength systems. Electron. Lett. 2013, 49, 281-282. [CrossRef]

74. Ye, N.; Gleeson, M.; Sadiq, M.; Roycroft, B.; Robert, C.; Yang, H.; Zhang, H.; Morrissey, P.; Mac Suibhne, N.; Thomas, K. InP-based active and passive components for communication systems at $2 \mu \mathrm{m}$. J. Lightwave Technol. 2015, 33, 971-975. [CrossRef]

75. Gunning, F.G.; Kavanagh, N.; Russell, E.; Sheehan, R.; Callagha, J.O. Key Enabling Technologies for Optical Communications at 2000 nm. Appl. Opt. 2018, 57, E64-E70. [CrossRef]

76. Chen, Y.; Chen, B. Design of InP-Based High-Speed Photodiode for 2- $\mu$ m Wavelength Application. IEEE J. Quantum Electron. 2019, 55, 1-8. [CrossRef]

77. Chen, Y.; Zhao, X.; Huang, J.; Deng, Z.; Cao, C.; Gong, Q.; Chen, B. Dynamic model and bandwidth characterization of InGaAs/GaAsSb type-II quantum wells PIN photodiodes. Opt. Express 2018, 26, 35034-35045. [CrossRef]

78. Tossoun, B.; Stephens, R.; Wang, Y.; Addamane, S.; Balakrishnan, G.; Holmes, A.; Beling, A. High-Speed InP-Based p-i-n Photodiodes With InGaAs/GaAsSb Type-II Quantum Wells. IEEE Photonics Technol. Lett. 2018, 30, 399-402. [CrossRef]

79. Tossoun, B.; Zang, J.; Addamane, S.J.; Balakrishnan, G.; Holmes, A.L.; Beling, A. InP-Based Waveguide-Integrated Photodiodes With InGaAs/GaAsSb Type-II Quantum Wells and 10-GHz Bandwidth at $2 \mu \mathrm{m}$ Wavelength. J. Lightwave Technol. 2018, 36, 4981-4987. [CrossRef]

80. Chen, Y.; Xie, Z.; Huang, J.; Deng, Z.; Chen, B. High-speed uni-traveling carrier photodiode for 2 mm wavelength application. Optica 2019, 6, 884-889. [CrossRef]

81. Srivastava, A.; DeWinter, J.; Caneau, C.; Pollack, M.; Zyskind, J. High performance GaInAsSb/GaSb p-n photodiodes for the 1.8-2.3 $\mu \mathrm{m}$ wavelength range. Appl. Phys. Lett. 1986, 48, 903-904. [CrossRef]

82. Mohammedy, F.M.; Deen, M.J. Growth and fabrication issues of GaSb-based detectors. J. Mater. Sci. Mater. Electron. 2009, 20, 1039-1058. [CrossRef]

83. Bowers, J.; Srivastava, A.; Burrus, C.; DeWinter, M.; Pollack, M.; Zyskind, J. High-speed GaInAsSb/GaSb PIN photodetectors for wavelengths to $2.3 \mu \mathrm{m}$. Electron. Lett. 1986, 22, 137-138. [CrossRef]

84. Andreev, I.; Serebrennikova, O.Y.; Sokolovskii, G.; Dudelev, V.; Ilynskaya, N.; Konovalov, G.; Kunitsyna, E.; Yakovlev, Y.P. High-speed photodiodes for the mid-infrared spectral region 1.2-2.4 $\mu \mathrm{m}$ based on GaSb/GaInAsSb/GaAlAsSb heterostructures with a transmission band of 2-5 GHz. Semiconductors 2013, 47, 1103-1109. [CrossRef]

85. Wun, J.M.; Wang, Y.W.; Chen, Y.H.; Bowers, J.E.; Shi, J.W. GaSb-Based p-i-n Photodiodes with Partially Depleted Absorbers for High-Speed and High-Power Performance at $2.5 \mu \mathrm{m}$ Wavelength. IEEE Trans. Electron Device 2016, 63, 2796-2801. [CrossRef]

86. Rogalski, A. Infrared Detectors; CRC Press: Boca Raton, FL, USA, 2010.

87. Singh, A.; Srivastav, V.; Pal, R. HgCdTe avalanche photodiodes: A review. Opt. Laser Technol. 2011, 43, 1358-1370. [CrossRef]

88. Beck, J.; Wan, C.-F.; Kinch, M.; Robinson, J. MWIR HgCdTe Avalanche Photodiodes; SPIE: Bellingham, WA, USA, 2001 ; Volume 4454.

89. Rothman, J.; Perrais, G.; Destefanis, G.; Baylet, J.; Castelein, P.; Chamonal, J.-P. High performance characteristics in pin MW HgCdTe e-APDs. In Proceedings of the Infrared Technology and Applications XXXIII, Orlando, FL, USA, 9-13 April 2007; p. 654219.

90. Perrais, G.; Derelle, S.; Mollard, L.; Chamonal, J.-P.; Destefanis, G.; Vincent, G.; Bernhardt, S.; Rothman, J. Study of the transit-time limitations of the impulse response in mid-wave infrared HgCdTe avalanche photodiodes. J. Electron. Mater. 2009, 38, 1790-1799. [CrossRef]

91. Kimukin, I.; Biyikli, N.; Kartaloglu, T.; Aytur, O.; Ozbay, E. High-speed InSb photodetectors on GaAs for mid-IR applications. IEEE J. Sel. Top. Quantum Electron. 2004, 10, 766-770. [CrossRef]

92. Giorgetta, F.R.; Baumann, E.; Graf, M.; Yang, Q.; Manz, C.; Kohler, K.; Beere, H.E.; Ritchie, D.A.; Linfield, E.; Davies, A.G. Quantum cascade detectors. IEEE J. Quantum Electron. 2009, 45, 1039-1052. [CrossRef]

93. Hofstetter, D.; Graf, M.; Aellen, T.; Faist, J.; Hvozdara, L.; Blaser, S. 23 GHz operation of a room temperature photovoltaic quantum cascade detector at $5.35 \mu \mathrm{m}$. Appl. Phys. Lett. 2006, 89, 061119. [CrossRef]

94. Zhou, Y.; Zhai, S.; Wang, F.; Liu, J.; Liu, F.; Liu, S.; Zhang, J.; Zhuo, N.; Wang, L.; Wang, Z. High-speed, room-temperature quantum cascade detectors at $4.3 \mu \mathrm{m}$. Aip Adv. 2016, 6, 035305. [CrossRef]

95. Dougakiuchi, T.; Edamura, T. High-speed quantum cascade detector with frequency response of over $20 \mathrm{GHz}$. In Proceedings of the SPIE Future Sensing Technologies, Tokyo, Japan, 13-14 November 2019; p. 111970R.

96. Huang, J.; Guo, D.; Chen, W.; Deng, Z.; Bai, Y.; Wu, T.; Chen, Y.; Liu, H.; Wu, J.; Chen, B. Sub-monolayer quantum dot quantum cascade mid-infrared photodetector. Appl. Phys. Lett. 2017, 111, 251104. [CrossRef]

97. Huang, J.; Guo, D.; Deng, Z.; Chen, W.; Liu, H.; Wu, J.; Chen, B. Midwave Infrared Quantum Dot Quantum Cascade Photodetector Monolithically Grown on Silicon Substrate. J. Lightwave Technol. 2018, 36, 4033-4038. [CrossRef]

98. Shen, Z.; Deng, Z.; Zhao, X.; Huang, J.; Yao, L.; Zou, X.; Cao, C.-F.; Gong, Q.; Chen, B. Long-wave infrared sub-monolayer quantum dot quantum cascade photodetector. J. Lightwave Technol. 2020. [CrossRef]

99. Lotfi, H.; Li, L.; Lei, L.; Ye, H.; Shazzad Rassel, S.; Jiang, Y.; Yang, R.Q.; Mishima, T.D.; Santos, M.B.; Gupta, J.A. High-frequency operation of a mid-infrared interband cascade system at room temperature. Appl. Phys. Lett. 2016, 108, 201101. [CrossRef]

100. Chen, Y.; Chai, X.; Xie, Z.; Deng, Z.; Zhang, N.; Zhou, Y.; Xu, Z.; Chen, J.; Chen, B. High-Speed Mid-Infrared Interband Cascade Photodetector Based on InAs/GaAsSb Type-II Superlattice. J. Lightwave Technol. 2020, 38, 939-945. [CrossRef] 
101. Xie, Z.; Huang, J.; Chai, X.; Deng, Z.; Chen, Y.; Lu, Q.; Xu, Z.; Chen, J.; Zhou, Y.; Chen, B. High-speed mid-wave infrared interband cascade photodetector at room temperature. Opt. Express 2020, 28, 36915-36923. [CrossRef]

102. Bigioli, A.; Gacemi, D.; Palaferri, D.; Todorov, Y.; Vasanelli, A.; Suffit, S.; Li, L.; Davies, A.G.; Linfield, E.H.; Kapsalidis, F. Mixing Properties of Room Temperature Patch-Antenna Receivers in a Mid-Infrared $(\lambda \approx 9 \mu \mathrm{m})$ Heterodyne System. Laser Photonics Rev. 2019, 14, 1900207. [CrossRef]

103. Huang, J.; Xie, Z.; Chen, Y.; Bowers, J.E.; Chen, B. High Speed Mid-Wave Infrared Uni-Traveling Carrier Photodetector. IEEE J. Quantum Electron. 2020, 56, 1-7. [CrossRef]

104. Cervera, C.; Rodriguez, J.; Perez, J.; Aït-Kaci, H.; Chaghi, R.; Konczewicz, L.; Contreras, S.; Christol, P. Unambiguous determination of carrier concentration and mobility for InAs/GaSb superlattice photodiode optimization. J. Appl. Phys. 2009, 106, 033709. [CrossRef]

105. Szmulowicz, F.; Elhamri, S.; Haugan, H.; Brown, G.; Mitchel, W. Carrier mobility as a function of carrier density in type-II InAs/GaSb superlattices. J. Appl. Phys. 2009, 105, 074303. [CrossRef]

106. Spears, D. Extending the Operating Temperature, Wavelength and Frequency Response of HgCdTe Heterodyne Detectors; Springer: Berlin, Germany, 1980.

107. Verie, C.; Sirieix, M. Gigahertz cutoff frequency capabilities of CdHgTe photovoltaic detectors at 10.6 $\mu \mathrm{m}$. IEEE J. Quantum Electron. 1972, 8, 180-184. [CrossRef]

108. Piotrowski, J. Uncooled operation of IR photodetectors. Opto-Electron. Rev. 2004, 12, 111-122.

109. Martyniuk, P.; Kopytko, M.; Grodecki, K.; Gawron, W.; Gomułka, E. High operating temperature long-wave HgCdTe detector for fast response operation: Optimization approach. In Proceedings of the 11th Conference on Integrated Optics: Sensors, Sensing Structures, and Methods, Szczyrk, Poland, 29 February-4 March 2016; p. 1003404.

110. Kopytko, M.; Kębłowski, A.; Madejczyk, P.; Martyniuk, P.; Piotrowski, J.; Gawron, W.; Grodecki, K.; Jóźwikowski, K.; Rutkowski, J. Optimization of a HOT LWIR HgCdTe Photodiode for Fast Response and High Detectivity in Zero-Bias Operation Mode. J. Electron. Mater. 2017, 46, 6045-6055. [CrossRef]

111. Vodopyanov, K.; Chazapis, V.; Phillips, C.; Sung, B.; Harris, J., Jr. Intersubband absorption saturation study of narrow III-V multiple quantum wells in the spectral range. Semicond. Sci. Technol. 1997, 12, 708. [CrossRef]

112. Brown, E.; McIntosh, K.; Smith, F.; Manfra, M. Coherent detection with a GaAs / AlGaAs multiple quantum well structure. Appl. Phys. Lett. 1993, 62, 1513-1515. [CrossRef]

113. Liu, H.; Jenkins, G.; Brown, E.; McIntosh, K.; Nichols, K.; Manfra, M. Optical heterodyne detection and microwave rectification up to $26 \mathrm{GHz}$ using quantum well infrared photodetectors. IEEE Electron Device Lett. 1995, 16, 253-255. [CrossRef]

114. Liu, H.; Li, J.; Brown, E.R.; McIntosh, K.A.; Nichols, K.B.; Manfra, M. Quantum well intersubband heterodyne infrared detection up to 82 GHz. Appl. Phys. Lett. 1995, 67, 1594-1596. [CrossRef]

115. Grant, P.; Dudek, R.; Wolfson, L.; Buchanan, M.; Liu, H. Ultra-high frequency monolithically integrated quantum well infrared photodetector up to $75 \mathrm{GHz}$. Electron. Lett. 2005, 41, 214-215. [CrossRef]

116. Grant, P.D.; Dudek, R.; Buchanan, M.; Liu, H.C. Room-Temperature Heterodyne Detection up to $110 \mathrm{GHz}$ With a Quantum-Well Infrared Photodetector. IEEE Photonics Technol. Lett. 2006, 18, 2218-2220. [CrossRef]

117. Palaferri, D.; Todorov, Y.; Bigioli, A.; Mottaghizadeh, A.; Gacemi, D.; Calabrese, A.; Vasanelli, A.; Li, L.; Davies, A.G.; Linfield, E.H.; et al. Room-temperature nine- $\mu \mathrm{m}$-wavelength photodetectors and GHz-frequency heterodyne receivers. Nature 2018, 556, 85-88. [CrossRef] [PubMed]

118. Rodriguez, E.; Mottaghizadeh, A.; Gacemi, D.; Palaferri, D.; Asghari, Z.; Jeannin, M.; Vasanelli, A.; Bigioli, A.; Todorov, Y.; Beck, M. Room-Temperature, Wide-Band, Quantum Well Infrared Photodetector for Microwave Optical Links at $4.9 \mu \mathrm{m}$ Wavelength. ACS Photonics 2018, 5, 3689-3694. [CrossRef]

119. Bigioli, A.; Armaroli, G.; Vasanelli, A.; Gacemi, D.; Todorov, Y.; Palaferri, D.; Li, L.; Davies, A.G.; Linfield, E.H.; Sirtori, C. Long-wavelength infrared photovoltaic heterodyne receivers using patch-antenna quantum cascade detectors. Appl. Phys. Lett. 2020, 116, 161101. [CrossRef]

120. Deng, Z.; Chen, B.; Chen, X.; Shao, J.; Gong, Q.; Liu, H.; Wu, J. Optical properties of beryllium-doped GaSb epilayers grown on GaAs substrate. Infrared Phys. Technol. 2018, 90, 115-121. [CrossRef]

121. Deng, Z.; Guo, D.; Huang, J.; Liu, H.; Wu, J.; Chen, B. Mid-wave infrared InAs/GaSb type-II superlattice photodetector with nBp design grown on GaAs substrate. IEEE J. Quantum Electron. 2019, 55, 1-5. [CrossRef]

122. Nunna, K.C.; Tan, S.L.; Reyner, C.J.; Marshall, A.R.J.; Liang, B.; Jallipalli, A.; David, J.P.; Huffaker, D.L. Short-wave infrared GaInAsSb photodiodes grown on GaAs substrate by interfacial misfit array technique. IEEE Photonics Technol. Lett. 2012, 24, 218-220. [CrossRef]

123. Ramiro, I.i.; Özdemir, O.; Christodoulou, S.; Gupta, S.; Dalmases, M.; Torre, I.; Konstantatos, G. Mid-and Long-Wave Infrared Optoelectronics via Intraband Transitions in PbS Colloidal Quantum Dots. Nano Lett. 2020, 20, 1003-1008. [CrossRef]

124. Livache, C.; Martinez, B.; Goubet, N.; Gréboval, C.; Qu, J.; Chu, A.; Royer, S.; Ithurria, S.; Silly, M.G.; Dubertret, B. A colloidal quantum dot infrared photodetector and its use for intraband detection. Nat. Commun. 2019, 10, 2125. [CrossRef] [PubMed]

125. Goubet, N.; Livache, C.; Martinez, B.; Xu, X.Z.; Ithurria, S.; Royer, S.; Cruguel, H.; Patriarche, G.; Ouerghi, A.; Silly, M. Wavefunction engineering in $\mathrm{HgSe} / \mathrm{HgTe}$ colloidal heterostructures to enhance mid-infrared photoconductive properties. Nano Lett. 2018, 18, 4590-4597. [CrossRef] [PubMed] 
126. De Iacovo, A.; Venettacci, C.; Colace, L.; Scopa, L.; Foglia, S. PbS Colloidal Quantum Dot Photodetectors operating in the near infrared. Sci. Rep. 2016, 6, 37913. [CrossRef] [PubMed]

127. Ding, Y.; Cheng, Z.; Zhu, X.; Yvind, K.; Dong, J.; Galili, M.; Hu, H.; Mortensen, N.A.; Xiao, S.; Oxenløwe, L.K. Ultra-compact integrated graphene plasmonic photodetector with bandwidth above $110 \mathrm{GHz}$. Nanophotonics 2020, 9, 317-325. [CrossRef]

128. Flory, N.; Ma, P.; Salamin, Y.; Emboras, A.; Taniguchi, T.; Watanabe, K.; Leuthold, J.; Novotny, L. Waveguide-integrated van der Waals heterostructure photodetector at telecom wavelengths with high speed and high responsivity. Nat. Nanotechnol. 2020, 15, 118-124. [CrossRef] [PubMed]

129. Long, M.; Gao, A.; Wang, P.; Xia, H.; Ott, C.; Pan, C.; Fu, Y.; Liu, E.; Chen, X.; Lu, W. Room temperature high-detectivity mid-infrared photodetectors based on black arsenic phosphorus. Sci. Adv. 2017, 3, e1700589. [CrossRef] 